The copyright of this thesis vests in the author. No quotation from it or information derived from it is to be published without full acknowledgement of the source. The thesis is to be used for private study or noncommercial research purposes only.

Published by the University of Cape Town (UCT) in terms of the non-exclusive license granted to UCT by the author. 


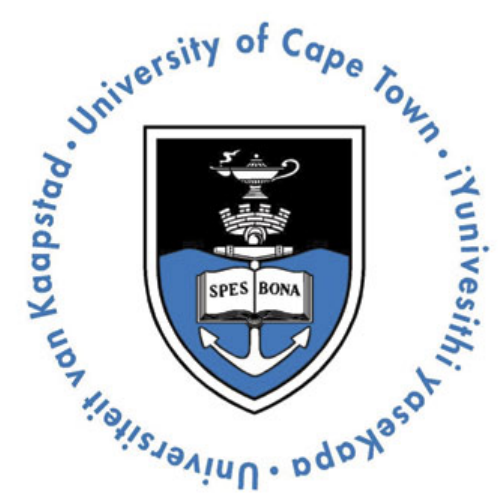

\title{
Hyperextension Injury of the Cervical Spine with Central Cord Syndrome
}

\author{
CRISPIN THOMPSON
}

THMCRI001

\author{
SUBMITTED TO THE UNIVERSITY OF CAPE TOWN in \\ fulfillment of the requirements for the degree \\ M Med Neurosurgery \\ Faculty of Health Sciences \\ UNIVERSITY OF CAPE TOWN
}

\section{Supervisor}

David Welsh

Division of Neurosurgery

Faculty of Health Sciences

University of Cape Town 


\section{Declaration}

I, Crispin Thompson, hereby declare that the work on which this dissertation/thesis is based is my original work (except where acknowledgements indicate otherwise) and that neither the whole work nor any part of it has been is being, or is to be, submitted for another degree in this or any other university.

I empower the university to reproduce for the purpose of research either the whole or any portion of the contents in any manner whatsoever.

Signature:

Date: $\quad 16$ April 2013 
Table of Contents

List of Abbreviations $\quad 5$

Glossary of Terms

Part A: Study Protocol 6

Introduction 6

$\begin{array}{ll}\text { Rationale for the study } & 7\end{array}$

$\begin{array}{ll}\text { Hypothesis } & 7\end{array}$

Methods $\quad 7$

Ethics and communication $\quad 9$

$\begin{array}{ll}\text { Logistics } & 10\end{array}$

Part B: Literature Review $\quad 11$

Objective 11

$\begin{array}{ll}\text { Search Strategy } & 12\end{array}$

Definition 12

History 13

$\begin{array}{ll}\text { Pathology } & 14\end{array}$

Imaging 15

$\begin{array}{ll}\text { Classification and Grading } 16 & 16\end{array}$

Management 20

$\begin{array}{ll}\text { Outcome } & 21\end{array}$

Part C: Manuscript $\quad 22$

Abstract 23

Introduction $\quad 24$

Patients and methods $\quad 25$

Results 28

Discussion 33

Conclusion $\quad 34$

References (Harvard Referencing Style) 35 
Part D: Appendix $\quad 41$

ASIA Standard Neurological Classification of

Spinal Cord Injury

FIM scale and guidelines $\quad 43$

Data Sheets 45

Human Research Ethics Committee Approval Letter 55

Dissertations Committee Approval Letter 56

$\begin{array}{ll}\text { MMed guidelines } & 57\end{array}$

$\begin{array}{ll}\text { Dissertation guidelines } & 63\end{array}$

European Spine Journal guidelines $\quad 69$ 


\section{List of Abbreviations}

AIS

ASCI

ASIA

CT

DRC

FIM

GSH

ICU

MMed

MRI

TCCS

UCT

ZPP
ASIA Impairment Scale

Acute Spinal Cord Injury

American Spinal Injury Association

Computerised Tomography

Departmental Research Committee

Functional Independence Measure

Groote Schuur Hospital

Intensive Care Unit

Masters Degree of Medicine

Magnetic Resonance Imaging

Traumatic Central Cord Syndrome

University of Cape Town

Zone of Partial Preservation

\section{Glossary of Terms}

Tetraplegia impairment of function, motor and/or sensory, in the cervical segments of the spinal cord, as a result of neural injury, affecting the upper limbs, trunk, lower limbs and pelvic organs (preferred to quadriplegia)

Paraplegia impairment of function, motor and/or sensory, in the thoracic, lumbar or sacral segment of the spinal cord, or cauda equina, as a result of neural injury, affecting the trunk, lower limbs and pelvic organs (depending on the level of the injury)

Dermatome an area of skin innervated by the sensory nerve root contributing to a single spinal cord segment

Myotome a unit of muscle fibres innervated by the motor nerve root arising from a single spinal cord segment 
Part A: Study Protocol

\section{Hyperextension Injury of the Cervical Spine with Central Cord Syndrome}

Principal Investigator: $\quad$ Dr Crispin Thompson

Supervisors: $\quad$ Dr David Welsh

\section{Introduction}

Traumatic Central Cord Syndrome (TCCS) is the most commonly encountered type of incomplete spinal cord injury ${ }^{[1,2]}$, accounting for nearly $45-70 \%$ of incomplete and $10-25 \%$ of all clinical syndromes following traumatic spinal cord injury ${ }^{[2,3,4]}$. TCCS typically occurs in patients with a narrow spinal canal and follows an acute hyperextension injury of the cervical spine ${ }^{[5]}$. The upper limbs are usually more severely affected than the lower limbs. Patients with a central cord type injury may present initially with a severe motor-sensory spinal cord injury, but have a much better prognosis for neurological improvement than other types of injury. Recovery of motor function is a fairly predictable feature of central cord syndrome, however it does not always lead to a good functional outcome. Surgical decompression and stabilisation of the injured cervical spine is an established strategy for managing TCCS, however not all patients require surgery in the acute stages or at all. 


\section{Rationale for the Study}

The optimal management strategy for Traumatic Central Cord Syndrome is not clearly defined within current surgical literature. The salient clinical features have been described for some time already ${ }^{[6]}$, however no clear prognostic indicators have been identified to assist in making management decisions. Several previous studies have suggested that early surgical intervention improves patient outcome ${ }^{[7-15]}$, however there is little consensus regarding patient selection and timing for surgery. The hope of this study is to identify useful clinical guidelines that assist in decision making and positively influence patient outcome.

\section{Hypothesis}

Patients that present to hospital following an acute spinal cord injury consistent with a traumatic central cord syndrome may benefit from a structured and clinically guided treatment strategy.

\section{Methods}

1. Study design

A retrospective folder review was performed of patients who presented to the ASCI unit at Groote Schuur Hospital over the five-year period from January 2004 to December 2008.

\section{Subject identification or selection}

A systematic review of the regional acute spinal cord injury (ASCI) register was performed and a list of patient names was generated based on information available in 
the patients' discharge summaries. All patients who presented to Groote Schuur Hospital (GSH) with a history consistent with having sustained a hyperextension type injury of the cervical spine and with a neurological deficit suggesting a central cord syndrome were included. Any patient who sustained an injury to the cervical spine that resulted in gross disruption of the bony architecture was excluded. These included vertebral body fractures with collapse, displaced pedicle fractures, facet joint fractures and / or dislocations and displaced lamina fractures.

\section{Data collection}

An electronic spreadsheet was designed for capture and collation of data collected from the ASCI register, patient folders, CT scans and MRI scans.

List of variables

- Demographic and epidemiological data: age, gender, employment status, smoking history, alcohol history, mode of injury and previous surgery or myelopathy.

- Pathology and clinical data: date of admission, duration of admission, level and severity of neurological injury and clinical course following injury.

- Imaging data: spinal column characteristics, spinal canal parameters, anatomical level of injury and associated injury phenomena.

- Management data: management strategy, timing of surgical intervention, nature of surgical intervention and occurrence of surgical or general complications.

- Outcome data: clinical progression, duration of hospital stay, discharge destinations, employment prognosis and mortality.

\section{Analysis}

All data were reviewed by the principal investigator and supervisor before being statistically analyzed. 


\section{Ethics and Communication}

The protocol for this study was presented to the Surgical Departmental Research Committee for approval, following which it was forwarded to the Human Research Ethics Committee with a copy of the synopsis for approval. The process of data collection and collation commenced as soon as the approval had been granted.

The clinical records of the patients identified on the Acute Spinal Cord Injury (ASCI) register were requested from the medical records department for review and analysis. The patient folders were reviewed in the medical records department and neurosurgical department in order to prevent the loss of documents and to maintain strict patient confidentiality. X-rays, CT scans and MRI scans were procured from the relevant storage facilities and signed out in accordance to departmental policies. The examination of radiological imaging required the use of light boards and computer based viewing software, and was carried out in the neurosurgical department using secured premises and apparatus. The imaging was returned to the radiology records department as soon as the review process was concluded. The collated data was recorded by electronic data sheet.

Patient confidentiality was, and will continued to be, maintained by following a strict protocol. The patient data was entered into a single computer within as short a time period as possible. The computer and research data file is secured by a password that is only know to the principal investigator. The patients' names and confidential information will not be used for publication purposes.

The results of the study will be submitted to a peer review journal for consideration for publication and will be the basis of the accompanying MMed dissertation. 


\section{Logistics}

This retrospective study was carried out during the normal working hours of the principal investigator, including one month of research allocated time, and after hours. There was no funding allocated for this study. 
Part B: Literature Review

\section{Traumatic Central Cord Syndrome (TCCS)}

1. Objective

2. Search Strategy

3. Definition

4. History

5. Pathology

6. Imaging

7. Classification and Grading

8. Management

9. Outcome

\section{Objective}

The objective of this literature review was to establish the consensus opinion of the research topic regarding the definition, incidence, clinical assessment and grading, management protocols and outcome measures. Although Traumatic Central Cord Syndrome (TCCS) has been recognised and treated for more than 50 years, several key issues are not well defined and clear management guidelines are lacking. With this literature review we hoped to identify these areas and formulate useful questions upon which to base the research protocol. 


\section{Search Strategy}

A primary literature search of electronic internet databases was carried out, spanning the period $01 / 01 / 2000$ to $31 / 12 / 2012$, using the following key phrases:

- Traumatic central cord syndrome

- Central cord injury

- Cervical spine hyperextension injury

Two hundred and twenty six articles were identified using the above criteria, but this number was subsequently reduced to 41 following a review of the abstracts. A secondary search was performed using articles listed in the references of the articles captured with the initial search strategy. The literature reviewed consisted of previous reviews of the topic and series reports.

\section{Definition}

Traumatic Central Cord Syndrome occurs almost exclusively in the cervical region and is the most commonly encountered type of incomplete spinal cord injury ${ }^{[1,2]}$, accounting for $45-70 \%$ of incomplete and $10-25 \%$ of all clinical syndromes following traumatic spinal cord injury ${ }^{[2-4]}$. TCCS is primarily a clinical diagnosis following a likely injury mechanism that can be strengthened further using appropriate diagnostic imaging modalities. Patients usually present with a combination of motor and sensory deficits. The upper extremities are disproportionately weaker than the lower extremities. Variable sensory loss occurs below the level of the injury. Patients may also have bladder dysfunction, usually urinary retention ${ }^{[6,16,17]}$.

TCCS typically occurs in three distinct patient groups ${ }^{[18]}$. The majority of patients are older than 50 years of age, have advanced degenerative spondylosis of the cervical spine with an associated narrowing of the spinal canal, and sustain a relatively minor hyperextension type of injury without bony fracture ${ }^{[9,16,18-28]}$. The second group comprises a younger patient population, with a normal cervical spine, and suffers a high-energy type injury. These patients often sustain a fracture and / or dislocation of 
the cervical spine ${ }^{[29,30]}$. The final and most recently described sub-group present with TCCS as a result of acute central cervical disc herniation ${ }^{[21,31]}$.

\section{History}

Sir William Thorburn, Consulting Surgeon at the Manchester Royal Infirmary, first reported the phenomenon in $1887^{[32]}$. In an article published in the journal Brain, Thorburn describes it as a "case of 'concussion of the spine' in which spinal cord symptoms supervened on a remote injury, a general shake, or a slight local injury".

In the early 1950's Richard C. Schneider and colleagues defined the clinical syndrome through a series of publications identifying the salient clinical features and discussing the indications and contra-indications for surgical intervention ${ }^{[6]}$. They described the syndrome of acute central cervical spinal cord injury as:

"In acute cervical spinal cord injuries, there is a syndrome that suggests acute central cervical spinal cord involvement. It is characterised by disproportionately more motor impairment of the upper than the lower extremities, by bladder dysfunction, usually by urinary retention, and by varying degrees of sensory loss below the level of the lesion. If the findings are caused by central cord destruction with bleeding, hematomyelia, there may be caudad or cephalad extension of the lesion with further progression of symptoms, perhaps culminating in complete tetraplegia or death. But if the symptoms are caused by concussion or contusion, with an edematous type of central cord involvement, there may be gradual return of function in a definite sequence. The amount of recovery depends on the degree of edema present compared to the extent of true destruction of nervous tissue. The lower extremities recover motor power first, bladder function returns next, and finally strength in the upper extremities reappears, with the finer finger movements coming back last. The varying degrees of sensory impairment do not follow any set pattern of recovery."

Taylor and Blackwood of the Department of Surgical Neurology, Brain Injuries Unit, Bangour Hospital illustrated the correlation between cervical spine injuries in patients with normal radiographs and hyperextension injuries as early as $1948^{[33]}$, noting in particular that suspicion should be heightened in the presence of facial lacerations or 
forehead contusions.

\section{Pathology}

Several investigators have demonstrated the biomechanical mechanisms of spinal cord injury in hyperextension injuries. As early as 1951 Taylor performed cadaveric myelography in specimens of varying ages ${ }^{[19]}$. He performed radiographs with the neck in flexion, neutral position and forced hyperextension and noted a distinct narrowing of the contrast column with the cervical spine in hyperextension. This narrowing was attributed to the compression and bulging of the ligamentum flavum with consequent impingement on the thecal sac. Taylor also noted that anteriorly located disc-osteophyte complexes found in degenerative cervical spines further reduced the cervical canal diameter and acted as points of counter pressure against which the spinal cord was compressed.

The pathological basis for TCCS is less clear-cut. The traditional explanation was based on the supposition that the anatomical distribution of the fibre tracts supplying the upper limbs are located more centrally, and therefore more severely compromised by a centrally located spinal cord contusion or haematoma, whereas the more peripherally situated fibres supplying the lower limbs remain relatively intact ${ }^{[6]}$. Schneider used the same theory in an attempt to explain the pattern of recovery and resultant residual neurological deficit. He postulated that an area of cord oedema surrounded the central zone of spinal cord destruction. As the oedema resolved with the passage of time the functional integrity of the more peripherally located fibres improved, thereby facilitating the sequential improvement of the lower limbs, bladder, arms and finally the hands.

Another theory, also proposed by Schneider, implicated vertebral artery insufficiency secondary to direct compression. The resultant ischaemic damage to the spinal cord was suggested as an alternate aetiology for acute neurological injury ${ }^{[20]}$.

More recent evidence suggests that the aforementioned explanations are flawed. The corticospinal tract appears to lose its somatotopic organisation distal to the midbrain ${ }^{[34]}$. Quencer and colleagues correlated magnetic resonance imaging (MRI) findings 
with post-mortem histopathological studies of individuals who had sustained central cord type injuries ${ }^{[35]}$. Not only were the MRI findings inconsistent with a centrally located parenchymal insult, but they also found a predominance of axonal injury within the white matter of the lateral columns of the cervical cord and that the centrally located grey matter was intact. Improvements in medical imaging technology, particularly MRI and MRI angiography, appear to contradict a vascular aetiology for TCCS ${ }^{[36,37]}$. Collectively, this suggests that the importance of the lateral corticospinal tracts for motor function in the distal upper limbs and hands and that direct injury is more likely responsible for the clinical syndrome encountered with these injuries ${ }^{[35-38]}$.

\section{Imaging}

Although the diagnosis of TCCS is fundamentally a clinical diagnosis, medical imaging plays an important role in confirming the diagnosis, describing the anatomical level and extent of the injury, identifying any associated pathology and assisting in planning appropriate management strategies.

Recommended radiographic examination includes the standard emergency room series of antero-posterior, lateral and odontoid view x-rays of the cervical spine ${ }^{[36]}$. This imaging series may show prevertebral soft tissue swelling, loss of intervertebral disc height, vertebral fractures or dislocations, alterations in vertebral alignment or widening of posterior inter-spinous distances - all of which may indicate an acute cervical spine injury with possible instability. Important pre-existing characteristics may also be clearly demonstrated, including degenerative changes, osteophytes and a stenotic cervical spinal canal - all of which would predispose the patient to sustaining TCCS ${ }^{[37]}$. Plain radiographs may appear normal, but this does not exclude an injury to the cervical spinal cord ${ }^{[39,40]}$.

Computer tomography (CT) scanning as a modality is gaining increasing popularity for the imaging of traumatic cervical spine injured patients. Improved image quality, reduced scanning times $\&$ the ability to digitally reconstruct images in any anatomical plane provides significant advantage over older generation CT scanners and plain 
radiographic imaging ${ }^{[41,42]}$. All of the aforementioned parameters can be easily and more accurately assessed, findings can be digitally recorded, and images can be manipulated and utilised for surgical planning. Surgical intervention can also be augmented with the integration of pre-operative and intra-operative images for improved surgical navigation and instrumentation.

Magnetic resonance imaging (MRI) is the most useful imaging modality for the assessment of TCCS, as with most traumatic spinal cord injuries ${ }^{[36,42]}$. Utilising the various imaging sequences afforded by MRI can assist with identifying or confirming the mechanism of injury, identify injury to adjacent muscles and ligaments, provide a clinically useful indication of spinal integrity or instability ${ }^{[39,43]}$, as well as identifying and quantifying the spinal cord injury ${ }^{[21,37]}$. Certain specific imaging characteristics have been shown to particularly useful. Signal hyperintensity within the prevertebral soft tissue on either T2-weighted or STIR image sequences are indicative of muscle and ligament disruption anterior to the vertebral column and correlates with intraoperative findings of damage to the anterior longitudinal ligament (ALL) ${ }^{[21]}$. The most common finding within the spinal cord is hyperintensity on a T2-weighted image sequence. This intramedullary high signal intensity identifies the anatomical level of the injury and represents either oedema of the spinal cord or microcystic degeneration and subsequent vacuolation. There is also a correlation between site of spinal instability and location of intramedullary high signal intensity ${ }^{[21,42]}$.

\section{Classification and Grading}

Spinal cord injuries can be classified in a number of ways, including severity of injury, pattern of injury and level of injury.

The severity of the injury ranges from a complete motor-sensory deficit, through a range of incomplete deficits with varying degrees of motor-sensory preservation, to no discernable deficit. TCCS is usually graded clinically according to either the American Spinal Injury Association (ASIA) Impairment Scale or the Frankel grading systems. The ASIA classification, derived from the Frankel scale, was first published 
as the International Standards for Neurological and Functional Classification of Spinal Cord Injury ${ }^{[44-47]}$. The patient is graded according to the motor and sensory
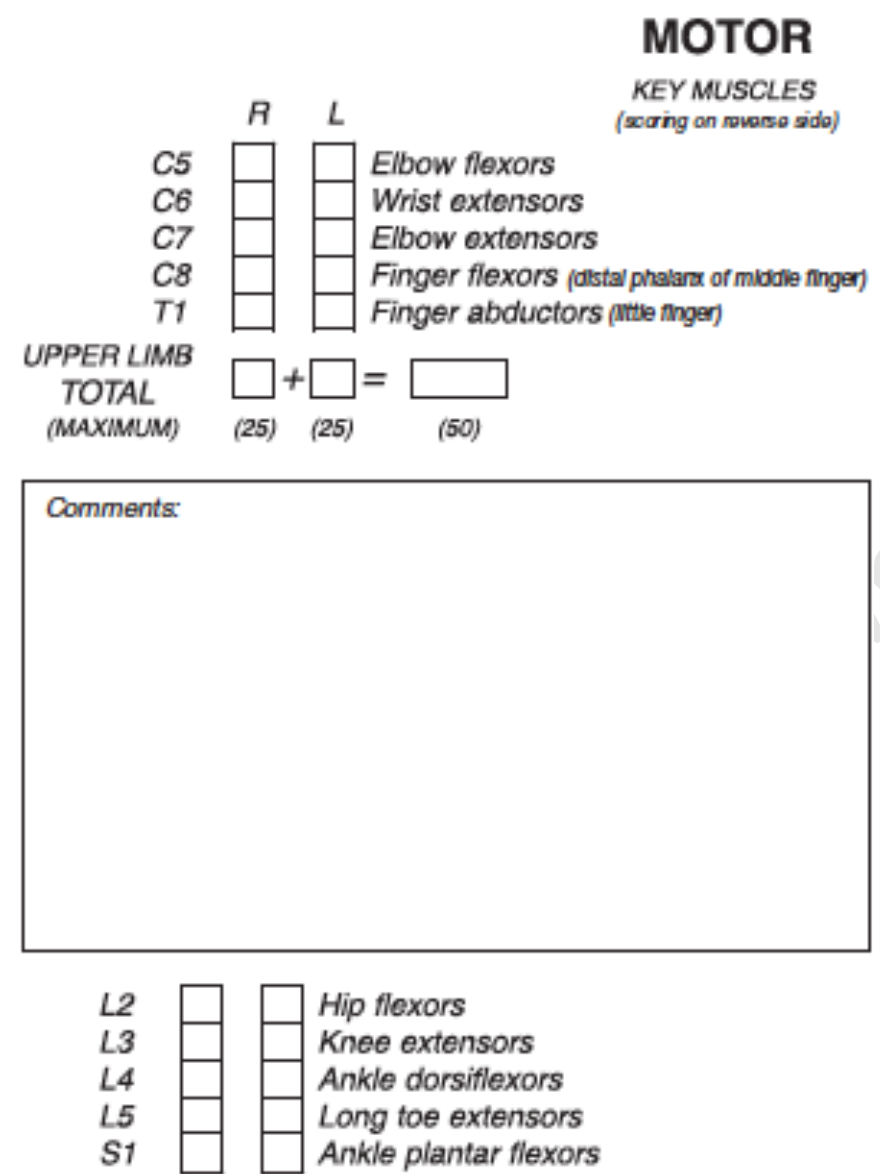

Voluntary anal contraction (Yes/ $/ \mathrm{No})$

Figure 1: Key motor groups and corresponding myotomes used in the ASIA Standard Neurological Classification of Spinal Cord Injury examination sheet

\begin{tabular}{|l|l|}
\hline Grade & Muscle Action \\
\hline 0 & Total paralysis \\
\hline 1 & Palpable or visible contraction \\
\hline 2 & Active movement with gravity eliminated \\
\hline 3 & Active movement against gravity \\
\hline 4 & Active movement against moderate resistance \\
\hline 5 & Active movement with full / normal power \\
\hline NT & Not tested \\
\hline
\end{tabular}

Table 1: Muscle power grading used for the ASIA Standard Neurological Classification of Spinal Cord Injury examination sheet 
scores measured in key muscles and sensory points. A pro-forma score sheet, published as the ASIA Standard Neurological Classification of Spinal Cord Injury examination template, is freely available with no restrictions regarding reproduction for clinical use (see appendix). The results are tabulated, calculated and converted into a scale from A to E according to severity.

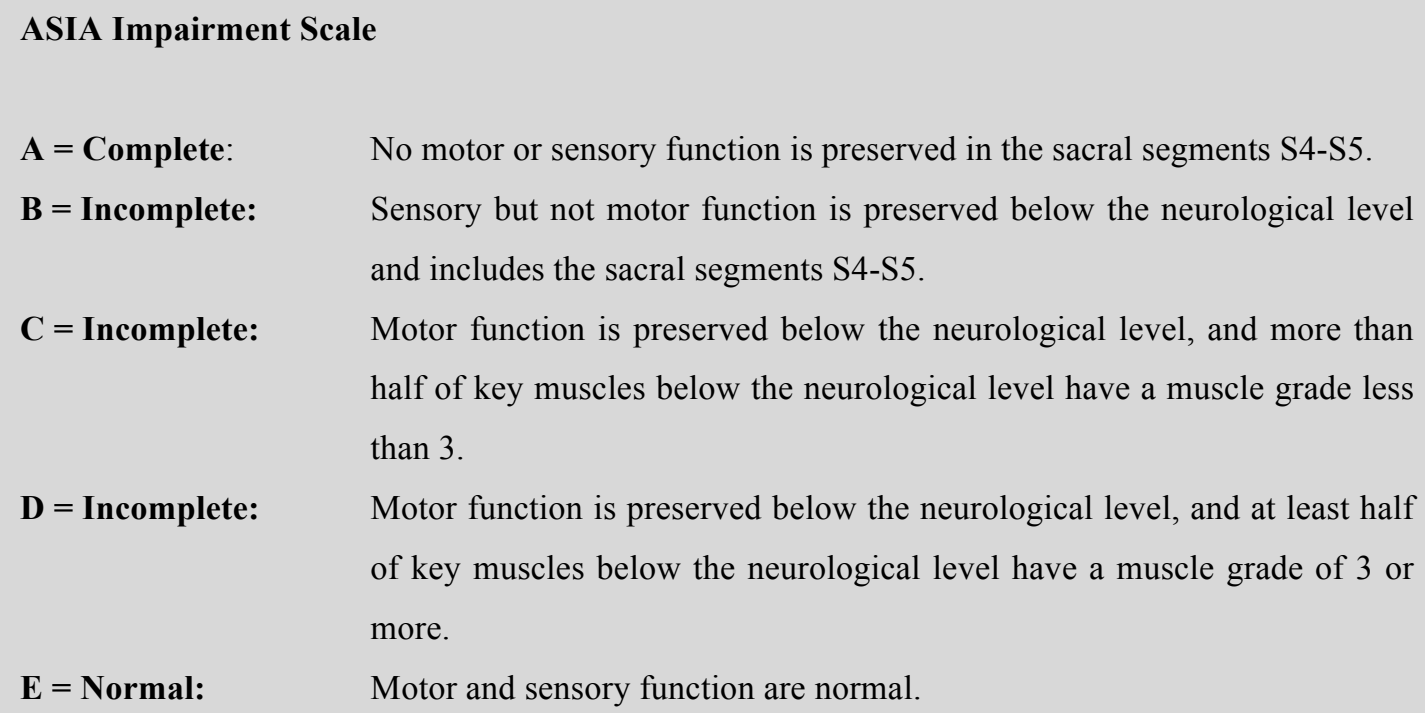

Table 2: ASIA Impairment Scale

The Frankel grade is similar to the ASIA scale, but reflects functional status rather than muscle power ${ }^{[48]}$. This distinction is particularly useful in grading TCCS as patients often have muscle power of 3 or more, but function may be significantly compromised by spasticity ${ }^{[2,22,49]}$.

\section{Frankel Grading System}
A Complete neurological injury, no motor or sensory function below level of injury
B Incomplete neurological injury, no motor function below level of injury, some sensory function below level of injury
C Incomplete neurological injury, some motor function below level of injury, but not functional, sensation may or may not be preserved
D Incomplete neurological injury, some motor function below level of injury, functional in nature, sensation may or may not be preserved
E Normal motor and sensory function below level of injury

Table 3: Frankel Grading System 
The level of the injury is usually described according to its anatomical, or structural, level as well as according to its neurological level. The anatomical level is determined using diagnostic imaging techniques such as CT and MRI ${ }^{[21,36,39,42,43]}$. There may be a discrepancy between the anatomical level and the neurological level of a number of spinal cord segments. The neurological level is further broken down into a motor level and a sensory level. The motor level refers to the most caudal myotome with full power. Key muscle groups, each representing one of ten myotomes, are tested in order to establish the level of the motor deficit.

The sensory level is determined by the most caudal of the body's twenty-eight dermatome with normal sensation. The ASIA Standard Neurological Classification of Spinal Cord Injury examination sheet requires testing for pinprick and light touch as a surrogate for normal sensory function. There is often a zone of partial preservation (ZPP) spanning several spinal cord segments where sensation is not completely absent, but also not normal. There may also be a difference in both motor and sensory level determinations between the right and left side of the body.
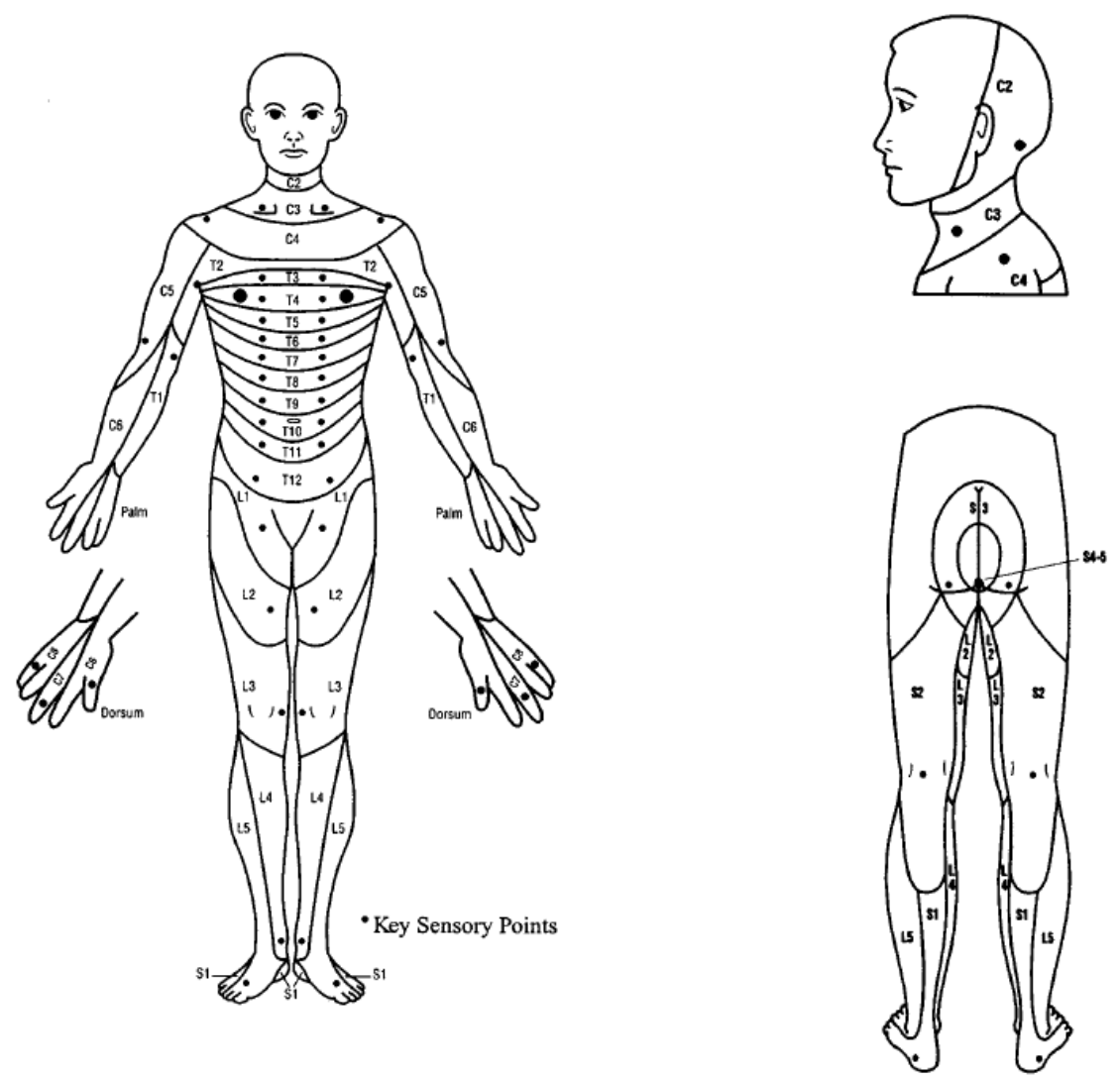

Figure 2: Schematic representation of sensory dermatomes as represented on the ASIA Standard Neurological Classification of Spinal Cord Injury examination sheet 


\section{Management}

The management of TCCS remains controversial. There is no doubt that surgical techniques and safety have improved tremendously since Schneider advocated a conservative treatment strategy ${ }^{[6]}$ and most clinicians involved in the management of TCCS agree that surgical decompression and stabilisation play an integral role, but there remains much debate around the timing and nature of the surgical intervention [4,9,12-15,18,22-26,28,36,50-60]. Several management options are implemented in specialist spine centres worldwide.

The non-operative management of patients with TCCS is an established treatment strategy, particularly in the scenario of improving neurological function ${ }^{[29]}$. Many patients present with an acutely injured, swollen cervical spinal cord encased within a multi-level degenerate stenotic spinal canal ${ }^{[61]}$. In addition, a significant portion of the typical patient population is older than 50 years of age ${ }^{[18]}$ and may have problematic medical comorbidities. To justify the added potential morbidity and mortality of surgical intervention requires evidence of clear clinical benefit. During the evolution of management practice a number of surgeons suggested a delayed approach, allowing the patient to attain a plateau phase of neurological recovery before deciding on the need for surgery ${ }^{[62,63]}$. This period of waiting also facilitates the optimisation of the patient's general medical condition and the management of comorbidities. The duration of the waiting period is not defined beyond the observation that the patient's neurological status has ceased to improve. Improvements in general patient care, anaesthetic practices and rehabilitative medicine are shortening this time interval and surgical intervention is occurring sooner. The evidence reviewed by Fehlings and colleagues ${ }^{[8,10-15]}$ supported surgery within 72 hours of injury, provided the patient was haemodynamically stable. Data have also shown that if operated on within 24 hours of injury there is a trend towards improved neurological status, a shorter ICU stay, a reduced incidence of associated complications and patients were discharged from hospital sooner ${ }^{[11,12,14,15,18,56,57]}$.

Surgical intervention is widely accepted as the standard of care in patients who present with worsening neurological deficit and radiological evidence of spinal cord compression and this is applied in the setting of TCCS ${ }^{[28,58]}$. Surgical reduction and 
stabilisation of fractures and dislocations occurring in conjunction with TCCS is also an established management strategy ${ }^{[28,56,62]}$.

\section{Outcomes}

Determining and grading patient outcomes in TCCS is a complex and somewhat imprecise process ${ }^{[22,49]}$. There is no outcome measure specific for TCCS, however a number of general spinal injury outcome measures can be used, either in isolation or in combination ${ }^{[22,49,56]}$. Repeat assessment using a previously utilised clinical grading score can provide an indication of how a patient's neurological function is progressing, or not. Both the ASIA Impairment Scale and the Frankel grading system are useful for this purpose ${ }^{[64]}$. Using the motor assessment component of the ASIA Impairment Scale, or ASIA Motor Score (AMS), helps identify trends of improvement specific to muscle strength. The general clinical trend is that of progressive neurological recovery with sequential improvement of lower limb function, followed by bladder function, and to a lesser degree improvement of upper limb function. The fine motor functions of the hands are the last feature of recovery, but are often a late finding if at all. Improvement in muscle strength is a hallmark of TCCS, but the degree of function achieved is often severely tempered by the increased muscle tone and overt spasticity of the major muscle groups ${ }^{[2,22,49]}$. In order to better quantify the specific components of each patient's recovery or rehabilitation, the Functional Independence Measure (FIM) ${ }^{[65]}$ (see appendix) has been used ${ }^{[22,23,56,65]}$. The FIM scoring system is useful for quantifying a patient's functional abilities and repeat assessments at pre-determined intervals provides an indepth analysis of both clinical and functional improvement as well as identifying further rehabilitative requirements. 
Part C: Manuscript

\title{
Hyperextension Injury of the Cervical Spine with Central Cord Syndrome
}

\author{
Crispin Thompson
}

Registrar, Division of Neurosurgery,

Faculty of Health Sciences,

University of Cape Town,

H53 Old Main Building,

Groote Schuur Hospital,

Main Road Observatory, 7295,

Cape Town,

South Africa

+27214066213 (tel)

+27828986561 (cell)

+27214066555 (fax)

crispin@sai.co.za

David Welsh

Consultant, Division of Neurosurgery,

Faculty of Health Sciences,

University of Cape Town,

H53 Old Main Building,

Groote Schuur Hospital,

Main Road Observatory, 7295 ,

Cape Town,

South Africa

+27214066213 (tel)

+27214066555 (fax)

capespine@gmail.com 


\section{Abstract}

Objective Traumatic Central Cord Syndrome (TCCS) is the most commonly encountered type of incomplete spinal cord injury. TCCS typically occurs in patients over the age of 50 years with a narrow spinal canal and follows an acute hyperextension injury of the cervical spine. Our objectives included the reporting of the demographics of the injured patients, their clinical course and outcomes, and the factors that may have influenced these outcomes.

Methods We conducted a retrospective folder review of patients who presented to our facility between January 2004 and December 2008 following hyperextension injury of the cervical spine and with the clinical manifestations of a central cord syndrome. Patient details were obtained from the acute spinal cord injury register at Groote Schuur Hospital and the patient folders, radiographs and magnetic resonance imaging films were reviewed. Predetermined data points were identified, tabulated and analysed, with only information from the injury related admission being included.

Results An ASIA motor score of $\geq 60$ on admission or discharge correlated with an $80 \%$ chance of being able to walk at discharge from hospital. An ASIA motor score of $\leq 50$ on admission correlated with an $80 \%$ chance of not walking at discharge. An ASIA motor score of $\leq 50$ at discharge meant a patient was not only unable to walk, but required placement in a spinal injury rehabilitation centre. Further, if a patient had a cervical spinal canal diameter of $\geq 8 \mathrm{~mm}$ they had a $50 \%$ chance of clinical improvement and nearly $80 \%$ chance of a functional outcome.

Conclusion The Groote Schuur Hospital patient population differs from the international norm, particularly with respect to age and mechanism of injury. The ASIA motor score and cervical spine canal diameter proved to be useful predictors of outcome. Within our patient group timing of surgery did not appear to influence outcome.

Keywords: $\quad$ Traumatic Central Cord Syndrome $\cdot$ Cervical spine hyperextension injury · Central cord injury 


\section{Introduction}

Traumatic Central Cord Syndrome (TCCS) is the most commonly encountered type of incomplete spinal cord injury ${ }^{[1-4]}$. Sir William Thorburn first reported the phenomenon in 1887 in an article published in Brain ${ }^{[4]}$. In the early 1950's Richard C. Schneider and colleagues further defined the clinical syndrome through a series of publications identifying the salient clinical features and discussing the indications and contra-indications for surgical intervention ${ }^{[6]}$. Several investigators have demonstrated the biomechanical mechanisms of spinal cord injury in hyperextension injuries. As early as 1951 Taylor performed cadaveric myelography in specimens of varying ages, examined radiographs with the neck in various positions and noted a distinct narrowing of the contrast column with the cervical spine in hyperextension ${ }^{[19]}$. This narrowing was attributed to the compression and bulging of the ligamentum flavum with consequent impingement on the thecal sac. Taylor also noted that anteriorly located disc-osteophyte complexes found in degenerative cervical spines further reduced the cervical canal diameter and acted as points of counter pressure against which the spinal cord was compressed.

The pathological basis for central cord syndrome is less clear-cut. The traditional explanation was based on the anatomical distribution of corticospinal tract fibres supplying the upper limbs being located more centrally, and therefore more severely compromised by a centrally located spinal cord contusion or haematoma, whereas the more peripherally situated fibres supplying the lower limbs remain relatively intact ${ }^{[6]}$. More recent evidence suggests that the aforementioned explanation is flawed. The corticospinal tract appears to lose its somatotopic organisation distal to the midbrain ${ }^{[34]}$. Quencer and colleagues correlated magnetic resonance imaging (MRI) findings with post-mortem histopathological studies of individuals who had sustained central cord type injuries ${ }^{[35]}$. Not only were the MRI findings inconsistent with a centrally located parenchymal insult, but they also found a predominance of axonal injury within the white matter of the lateral columns of the cervical cord and that the centrally located grey matter was intact. Collectively, this suggests that the importance of the lateral corticospinal tracts for motor function in the distal upper limbs and hands and that direct injury is more likely responsible for the clinical syndrome encountered with these injuries. 
Much discussion and disagreement centres on the surgical management of central cord syndrome ${ }^{[4,6,9,12-15,18,22-26,28,36,50-60]}$. Few fixed indications for surgical intervention are unanimous, however current consensus agrees that there is an established role for surgery. There is further debate as to whether timing of surgery changes the likelihood of improved neurological outcome. Evidence has been presented to support surgical intervention within $24-72$ hours of injury ${ }^{[9-15]}$, particularly for patients with vertebral fractures or dislocations, unstable injuries or intervertebral disc herniation [23,51]. Others contend that it is better to delay surgery until the patient reaches a plateau phase of neurological improvement ${ }^{[62,63]}$. There is more agreement amongst treating surgeons regarding the goals and nature of surgical intervention.

\section{Patients and Methods}

Nine hundred and fifty one patients were admitted to the regional acute spinal cord injury (ASCI) unit at Groote Schuur Hospital between January 2004 and December 2008. A systematic review of the ASCI register was performed and a list of patient names was generated based on information available in the patients' discharge summaries. All patients with a history consistent with having sustained a hyperextension type injury of the cervical spine and with a neurological deficit suggesting a central cord syndrome were included. Any patient who sustained an injury to the cervical spine that resulted in gross disruption of the bony architecture was excluded. These included vertebral body fractures with collapse, displaced pedicle fractures, facet joint fractures and / or dislocations and displaced lamina fractures.

Thereafter the patient notes were reviewed for the injury related admission period. A predetermined list of data points were collected from the folders using doctors admission clerking notes, in-patient notes, radiology reports, surgeons' operation notes where applicable, nursing notes, physiotherapy notes and doctor's discharge summaries. Data of interest included limited patient demographics, epidemiological data, information regarding injury mechanism, level of spinal and neurological injury, extent of neurological injury, associated cervical spine injuries and pathologies, 
admission and discharge ASIA (American Spinal Injury Association) Impairment Scale ${ }^{[44-47]}$ and Frankel ${ }^{[48]}$ grading, admission and discharge ASIA motor scores, radiological characteristics of the injury, clinical course, presence and nature of surgical intervention, any injury related complications, and limited discharge information. The information was collected using a secure electronic database program.

\section{Frankel Grading System}

A Complete neurological injury, no motor or sensory function below level of injury

B Incomplete neurological injury, no motor function below level of injury, some sensory function below level of injury

C Incomplete neurological injury, some motor function below level of injury, but not functional, sensation may or may not be preserved

D Incomplete neurological injury, some motor function below level of injury, functional in nature, sensation may or may not be preserved

E Normal motor and sensory function below level of injury

Table 1: Frankel Grading System

\section{ASIA Impairment Scale}

A = Complete: $\quad$ No motor or sensory function is preserved in the sacral segments S4-S5.

B = Incomplete: $\quad$ Sensory but not motor function is preserved below the neurological level and includes the sacral segments S4-S5.

$\mathbf{C}=$ Incomplete: $\quad$ Motor function is preserved below the neurological level, and more than half of key muscles below the neurological level have a muscle grade less than 3 .

D = Incomplete: $\quad$ Motor function is preserved below the neurological level, and at least half of key muscles below the neurological level have a muscle grade of 3 or more.

$\mathbf{E}=$ Normal: $\quad$ Motor and sensory function are normal.

Table 2: ASIA Impairment Scale

X-ray and magnetic resonance imaging (MRI) films of the relevant patients were reviewed for any previously overlooked exclusion criteria, evidence of associated soft tissue injury, the presence of acute cervical disc injuries, degenerative changes and any pre-existing cervical spine pathology. Cervical canal diameter was measured on the MRI film using a wall mounted light box, at the level of maximal narrowing 
corresponding to the neurological injury, on the closest to midline sagittal slice on a T2 weighted image using the provided scale conversion. Accuracy was checked using digital measuring techniques on a DICOM viewing system and was found to be to within 0.5 millimetres.

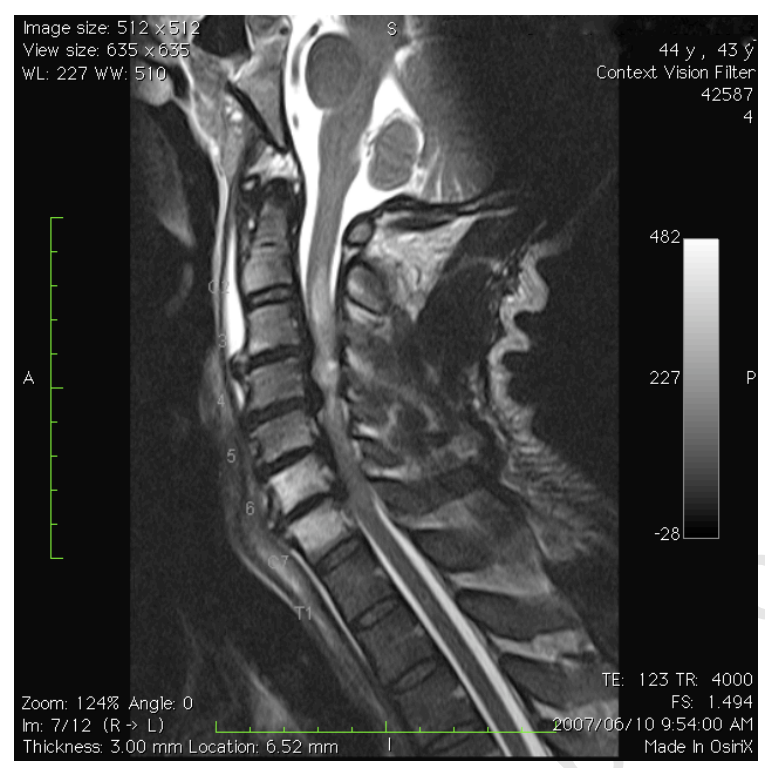

Figure 1: T2 weighted MR image showing a prevertebral fluid collection, oedema of the C6 \& C7 vertebral bodies, spondylotic stenosis of the cervical spinal canal from $\mathrm{C} 3-7$, disc-osteophyte complexes, with compression of the spinal cord and resultant oedema

Incomplete patient records and imaging further excluded 152 patients. A total of 50 patients and 51 admission episodes were accumulated, with one patient sustaining two central cord type injuries within the period covered. The collected data were tabulated and interrogated by the principal investigator and supervisor in order to identify any useful trends. The data were analysed using SPSS software (version 19.0, SPSS Incorporated, Chicago, Illinois, USA). Chi-squared analysis was used to assess the relationship between cervical canal measurements and the likelihood of requiring surgical intervention, the likelihood of clinical improvement and the likelihood of achieving a functional outcome grade. Chi-squared analysis was used to assess the relationship between patient age and the likelihood of requiring surgical intervention. Significance was set at a $P$ value of $<0.05$. 


\section{Results}

The selected patient population of 51 admission episodes comprised 42 males and 9 females. The age range was 13-72 years, with a mean age of 41.4 years and a median age of 42.5 years. The scenario of a low energy frontal impact to the head resulting in hyperextension and spinal cord compromise was seen in a relatively small percentage of our patients. A much greater number of high-energy injuries were recorded, including motor vehicle accidents, major falls, violent assault and heavy blunt trauma.
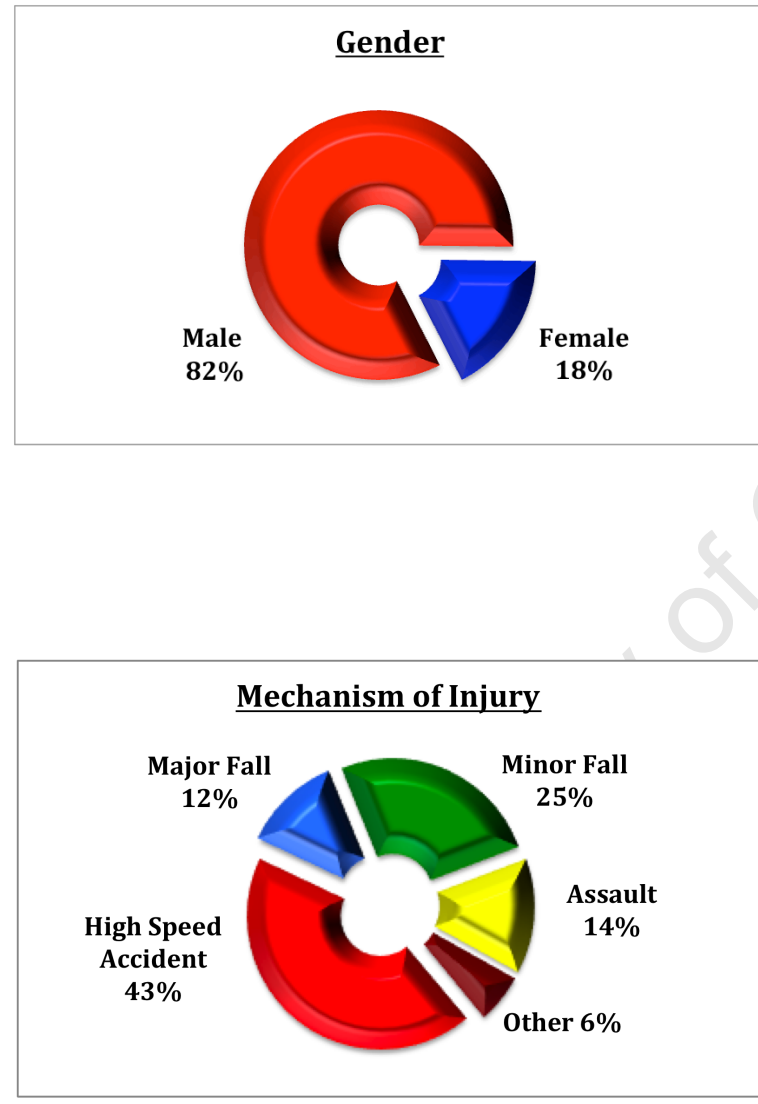

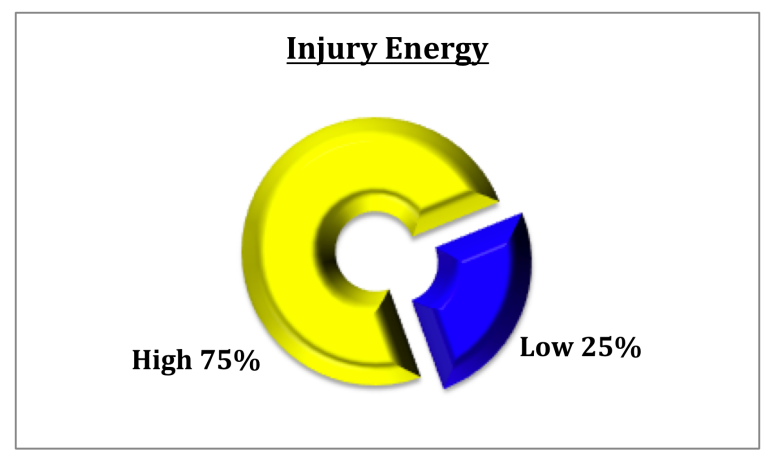

Figure 4: Energy of injury 
Only one patient gave a history of pre-existing myelopathy and one patient had undergone previous cervical spine surgery. Twenty eight individuals were employed at the time of their injury, 34 smoked on a regular basis and only 3 admitted that alcohol consumption may have played a role in sustaining the injury.

Eight patients presented with a motor-sensory complete spinal cord injury, whilst the remaining 43 had an incomplete deficit. The admission neurological status of the patients was scored according to both the ASIA Impairment Scale and Frankel Grading System. A discharge Frankel grade of D or E was regarded as a functional outcome for this study.

The most common vertebral level of injury was at the $C 3 / 4$ disc space $(n=16)$. The most common neurological level was C4 $(n=26)$, followed by C5 $(n=13)$. Despite the high incidence of high cervical cord injury, no patient was dependent on a ventilator for respiration.

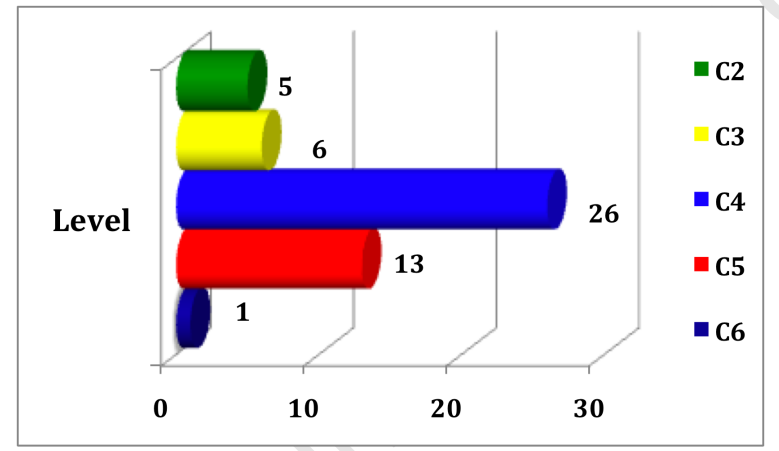

Figure 5: Neurological level of injury

The admission and discharge grading scores were compared in order to identify the sub-group of patients most likely to improve or benefit from more aggressive management strategies. Notable changes in Frankel grading included two patients improving from $\mathrm{A}$ to $\mathrm{B}$ and $\mathrm{A}$ to $\mathrm{C}$ respectively, two patients improving from $\mathrm{B}$ to $\mathrm{C}$ and $\mathrm{B}$ to $\mathrm{E}$ respectively, and a further five patients improving to an E grading, two from a $\mathrm{C}$ grade and three from a $\mathrm{D}$ grade. The greatest degree of improvement was primarily from Frankel grades $\mathrm{C}$ and $\mathrm{D}$ to grades D and E. None of the patients deteriorated to a worse grade on either scoring system. ASIA motor scores were recorded on both admission and on discharge. An admission ASIA motor score of 50 
or less implied an $80 \%$ chance of not being able to walk by discharge and a score of 60 or more on admission or discharge implied an $80 \%$ chance of being independently mobile. A discharge ASIA motor score of 50 or less had a $0 \%$ prevalence of walking or being discharged home in our patient series.

\begin{tabular}{|l|l|l|l|l|}
\hline \multirow{2}{*}{$\begin{array}{l}\text { Neurological } \\
\text { Status }\end{array}$} & \multicolumn{2}{|l|}{ ASIA } & Frankel \\
\cline { 2 - 5 } & Admission & Discharge & Admission & Discharge \\
\hline A & 8 & 6 & 8 & 6 \\
\hline B & 4 & 3 & 4 & 3 \\
\hline C & 15 & 8 & 24 & 10 \\
\hline D & 23 & 27 & 14 & 25 \\
\hline E & 1 & 7 & 1 & 7 \\
\hline
\end{tabular}

Table 3: Comparison of admission and discharge neurological status

We reviewed the MRI images in order to identify any pre-existing abnormalities, as there is a well-described association between an underlying cervical spine pathology, particularly stenosis, and TCCS in the elderly population ${ }^{[9,16,18-28]}$. Within our patient group the overall incidence of normal cervical spines was $47 \%$, whereas $39 \%$ had stenosis of the cervical canal, $12 \%$ had a pre-existing autofusion and one patient had ossified posterior longitudinal ligament. The level of neurological injury correlated predictably with the level of vertebral pathology. Over $80 \%$ of patients under 40 years had normal cervical spine architecture, with only four patients having a stenotic cervical canal. Of the patients older than 40 years, $79 \%$ of individuals had clear radiological evidence of pre-existing pathology.

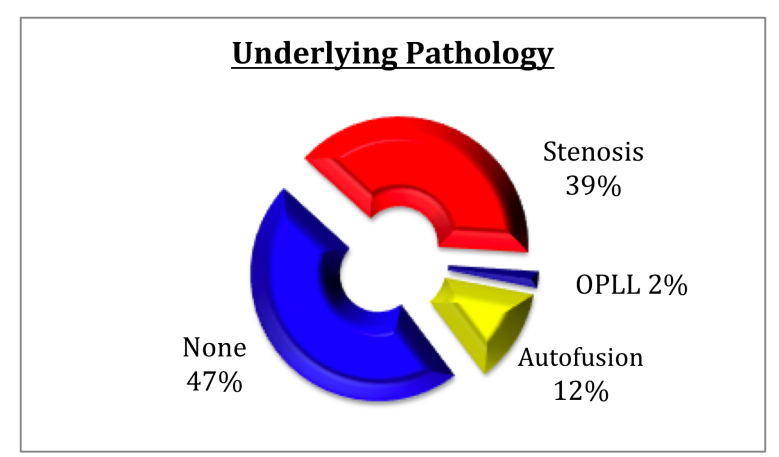

Figure 6: Prevalence of pre-existing structural cervical spine anomaly 
On MRI we measured both mid-sagittal canal and cord diameter at the level of maximum compromise and at the next normal level above and below the injury. The average canal and cord diameters at normal levels were $11,3 \pm 1.6 \mathrm{~mm}$ and $7.1 \pm 1 \mathrm{~mm}$ respectively. We looked at clinical improvement and function, based on admission and discharge Frankel grades, with a canal diameter $<8 \mathrm{~mm}$ and $\geq 8 \mathrm{~mm}$ (chosen to accommodate average cord diameter $+1 \mathrm{SD})$. Those patients with a canal diameter of $\geq 8 \mathrm{~mm}$ had a statistically significant chance of not requiring surgery ( $P$ value 0,00005 ) and of achieving a functional outcome ( $P$ value 0,02030$)$. The correlation between canal diameter and clinical improvement did not achieve statistical significance $(P$ value 0,45735 )

\begin{tabular}{|l|l|l|l|l|l|l|}
\hline \multirow{2}{*}{$\begin{array}{l}\text { Canal diameter at } \\
\text { Level of Injury }\end{array}$} & \multicolumn{2}{|l|}{ Surgery } & \multicolumn{2}{l|}{ Improved Clinically } & \multicolumn{2}{l|}{ Functional Outcome } \\
\cline { 2 - 7 } & Yes & No & Yes & No & Yes & No \\
\hline$<8 \mathrm{~mm}(53 \%)$ & $25(93 \%)$ & $2(7 \%)$ & $10(37 \%)$ & $17(63 \%)$ & $13(48 \%)$ & $14(52 \%)$ \\
\hline$\geq 8 \mathrm{~mm}(47 \%)$ & $6(25 \%)$ & $18(75 \%)$ & $12(50 \%)$ & $12(50 \%)$ & $19(79 \%)$ & $5(21 \%)$ \\
\hline
\end{tabular}

Table 4: Comparison of mid-saggital cervical spine canal diameter in relation to surgery and outcome

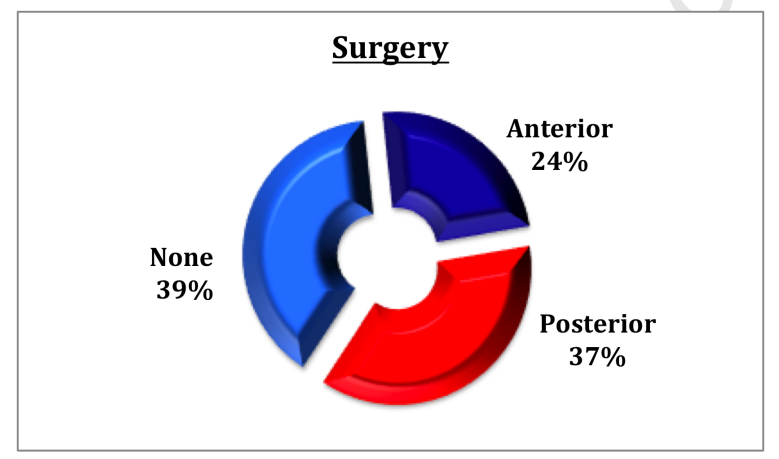

Figure 7: Surgical approaches

Thirty one patients underwent surgery for the management of the injury. Twelve patients were operated on via an anterior approach, the primary indication being discectomy and fusion, and 19 patients had a decompressive laminectomy via a posterior approach, with or without fusion. Time from injury to operation ranged from 1 to 108 days, with a median interval of 11 days. Twenty patients were managed nonoperatively. Only one of the patients in our series had early surgical intervention (within 24 hours of injury), improved from a Frankel grade $\mathrm{C}$ to grade D, was walking at the time of discharge and was able to go home. Seventeen patients had surgery 
within two weeks of their injury, 8 improved at least one Frankel grade and 9 did not improve. Thirteen patients were operated on more than two weeks after sustaining their injury, 4 improved at least one Frankel grade and 9 did not improve. Four patients were operated on more than 30 days following injury and none improved clinically. Ten of the patients managed non-surgically improved at least one Frankel grade and 10 did not improve. A functional outcome was documented in 17 out of 31 surgically managed patients and 15 out of 20 non-surgically managed patients. One of the patients managed non-surgically was discharged with a Frankel grade D deficit and an ASIA motor score of 95, but sustained a second low energy injury seven months later and returned with a Frankel grade C and ASIA motor score of 25. On discharge from the second admission, following a decompressive laminectomy, he had a Frankel grade $\mathrm{C}$ deficit, an ASIA motor score of 48 and was unable to walk. The only surgical complication encountered was one superficial wound infection.

\begin{tabular}{|l|l|l|l|l|l|}
\hline Management vs Outcome & Total & Improvement & No Improvement & Functional & Non-Functional \\
\hline Surgical ( $\leq 24$ hours) & 1 & 1 & 0 & 1 & 0 \\
\hline Surgical ( $\leq 14$ days) & 17 & 8 & 9 & 9 & 8 \\
\hline Surgical ( $>14$ days) & 13 & 4 & 9 & 7 & 6 \\
\hline Non-surgical & 20 & 10 & 10 & 15 & 5 \\
\hline
\end{tabular}

Table 5: Relationship between surgical intervention, clinical improvement and outcome

At discharge from our ASCI unit 51\% of patients were able to mobilise independently or with the aid of a walking frame, $37 \%$ of patients were able to return home directly, and $14 \%$ of the previously employed individuals were able to return to work. The clinical and functional performance of the patients was only assessed on admission and again on discharge from our hospital, therefore the length of follow-up is short and further changes in functional performance are not accounted for. Only one patient died during the injury related admission.

Patient age of 40 years or less was shown to be a reliable indicator of not requiring surgery, and vice versa (P value 0,00005 ).

\begin{tabular}{|l|c|l|}
\hline Age vs Management & Surgical & Conservative \\
\hline$\leq \mathbf{4 0}$ years (43\%) & $6(27 \%)$ & $16(73 \%)$ \\
\hline$>\mathbf{4 0}$ years (57\%) & $25(86 \%)$ & $4(14 \%)$ \\
\hline
\end{tabular}

Table 6: Relationship between patient age and management strategy 


\section{Discussion}

The age demographic of our patient cohort varies significantly from the typical elderly male patient population described in the literature ${ }^{[9,16,18-28]}$. This may be explained, at least in part, by the second noticeable difference. The injury sustained by our patients more often involved a greater force than is typically described. This might result in fewer elderly patients surviving the initial insult as well as younger patients, with structurally normal cervical spine canals, injuring their spinal cords and exhibiting an equivalent neurological deficit.

The measurement of the mid-sagittal cervical canal diameter, at the level of the injury, was performed in order to identify a predictor of outcome. The postulate supposed that if there was sufficient canal volume to accommodate a swollen spinal cord, and allow for spontaneous recovery, then surgery might be avoided. We grouped our patients according to a canal diameter of $<8 \mathrm{~mm}$ and $\geq 8 \mathrm{~mm}$. The dimension was chosen to coincide with the mean cervical spinal cord diameter plus one standard deviation. Patients with a canal diameter $\geq 8 \mathrm{~mm}$ had a much lower likelihood of requiring surgery, showed an increased prevalence of clinical improvement and experienced a greater percentage of functional outcome.

Our ASCI unit receives the bulk of its referrals from centres that do not offer any surgical management prior to transfer. This, coupled with resource and logistical restraints within our hospital, precludes the vast majority of patients from undergoing surgery within 24 hours of sustaining their injury. The clinical and functional performance of the patients was assessed on admission and again on discharge from our hospital, therefore the length of follow-up is short and further changes in functional performance are not accounted for. The single patient that was operated on within 24 hours experienced both a neurological and a functional improvement in keeping with the suggestions that early surgery is preferable ${ }^{[8-15]} .47 \%$ of patients improved clinically following surgery within two weeks of injury as opposed to $30 \%$ operated on after two weeks. This trend of neurological improvement for the patients operated on within 14 days did not translate into a trend of improved functional outcome. $50 \%$ of the patients managed non-surgically showed neurological improvement. The superior rate of functional recovery in the non-surgical group 
reflects a potential selection bias for surgery amongst the more severely injured patients. These numbers are neither supportive nor contrary to surgical intervention. We excluded patients who required surgery for injury related structural instability in an attempt to better identify neurological indications for surgery.

We quantified the neurological deficit sustained by our patients using both the ASIA and Frankel scoring systems in order to assess which would better reflect their injury pattern and help guide management decisions. The key differences between the two systems are found in the corresponding sub-groups C and D. The ASIA Impairment Scale classifies patients according to muscle power below the level of injury whereas the Frankel Grading System stratifies patients according to functional use of muscle groups below the level of injury. In our opinion the latter scale may prove more useful in scoring patients with TCCS as they may have power of $3 / 5$ or more in the limbs without functional use of the involved limbs, usually as a result of spasticity ${ }^{[2,22,49]}$.

\section{Conclusion}

Patients that present to Groote Schuur Hospital following a traumatic central cord injury are not typically representative of the TCCS population described in the international literature. The first key difference is the age group. Two thirds of our patients were under the age of 50 years, whereas the majority of patients are usually over the age of 50 years. Secondly, three quarters of our patients suffered a highenergy mechanism of injury, rather than the typical low energy mechanism. The admission and discharge ASIA motor scores proved useful for predicting functional outcome. Patient age correlated with whether surgery was required. The mid-sagittal cervical spine canal diameter correlated with the need for surgical intervention and functional status at the time of discharge. We were unable to offer any clarity on the benefits of emergency surgery, however the timing of subsequent surgery did not appear to affect the functional outcome within our group. 


\section{References}

1. GREENBERG, Mark S. 2001. Handbook of Neurosurgery. $5^{\text {th }}$ ed. New York: Thieme New York

2. MCKINLEY, W., SANTOS, K., MEADE, M., BROOKE, M.T. 2007. Incidence and outcomes of spinal cord injury clinical syndromes. J Spinal Cord Med 30(3):215-224

3. BOSCH, A., STAUFFER, E.S., NICKEL, V.L. 1971. Incomplete traumatic quadriplegia: a ten-year review. JAMA 216(3):473-478

4. MERRIAM, W.F., TAYLOR, T.K., RUFF, S.J. 1986. A reappraisal of acute traumatic central cord syndrome. J Bone Joint Surg Br 68:708-713

5. BEERS, M.H., PORTER, R.S., JONES, T.V., KAPLAN, J.L., BERKWITS, M. 2006. The Merck Manual of Diagnosis and Therapy. $18^{\text {th }}$ ed. New Jersey: Merck Research Laboratories

6. SCHNEIDER, R.C., THOMPSON, J.M., BEBIN, J. 1958. The syndrome of acute central cervical spinal cord injury. J Neurol Neurosurg Psychiat 21(3):216-227

7. GUEST, J., ELERAKY, M.A., APOSTLIDES, P.J., DICKMAN, C.A., SONNTAG, V.K. 2002. Traumatic central cord syndrome: results of surgical management. J Neurosurg 97(1 Suppl):25-32

8. FEHLINGS, M.G., PERRIN, R.G. 2005. The role and timing of early decompression for cervical spinal cord injury: update with a review of recent clinical evidence. Injury 36(Suppl 2):B13-26

9. YAMAKAZI, T., YANAKA, K., FUJITA, K., KAMEZAKI, T., UEMURA, K., NOSE, T. 2005. Traumatic central cord syndrome: analysis of factors affecting outcome. Surg Neurol 63(2):95-100

10. FEHLINGS, M.G., SEKHON, L., TATOR, C. 2001. The role and timing of decompression in acute spinal cord injury: what do we know? What should we do? Spine 26:101-110

11. FEHLINGS, M.G., PERRIN, R.G. 2006. The timing of surgical intervention in the treatment of spinal cord injury: a systematic review of recent clinical evidence. Spine 31:28-35 
12. FEHLINGS, M.G., VACCARO, A., WILSON, J.R., SINGH, A., CADOTTE, D.W., HARROP, J.S., AARABI, B., SHAFFREY, C., DVORAK, M., FISHER, C., ARNOLD, P., MASSICOTTE, E.M., LEWIS, S., RAMPERSAUD, R. 2012. Early versus delayed decompression for traumatic cervical spinal cord injury: Results of the surgical timing in acute spinal cord injury study (STASCIS). Plos One 7(2): 32037

13. WILSON, J.R., FEHLINGS, M.G. 2011. Emerging approaches to the surgical management of acute traumatic spinal cord injury. 2011 Neurotherapeutics 8:187194

14. FURlan, J.C., NOONAN, V., CADOTTE, D.W., FEHLINGS, M.G. 2011. Timing of decompressive surgery of spinal cord after traumatic spinal cord injury: Examination of pre-clinical and clinical studies. J Neurotraum 28:1371-1399

15. CADOTTE, D.W., FEHLINGS, M.G. 2011. Spinal cord injury: a systematic review of current treatment options. Clin Orthop Relat Res 469:732-741

16. POUW, M.H., VAN MIDDENDORP, J.J., VAN KAMPEN, A., HIRSCHFELD, S., VETH, R.P.H., CURT, A., HOSMAN, A.J.F., VAN DE MEENT, H. 2010. Diagnostic criteria of traumatic central cord syndrome. Part 1: A systematic review of clinical descriptors and scores. Spinal Cord 48:652-656

17. VAN MIDDENDORP, J.J., POUW, M.H., HAYES, K.C., WILLIAMS, R., CHHABRA, H.S., PUTZ, C., VETH, R.P.H., GEURTS, A.C.H., AITO, S., KRIZ, J., MCKINLEY, W., VAN ASBECK, F.W.A., CURT, A., FEHLINGS, M.G., VAN DE MEENT, H., HOSMAN, A.J.F. 2010. Diagnostic criteria of traumatic central cord syndrome. Part 2: A questionnaire survey among spine specialists Spinal Cord 48:657-663

18. STEVENS, E.A., MARSH, R., WILSON, J.A., SWEASY, T.A., BRANCH, C.L., POWERS, A.K. 2010. A review of surgical intervention in the setting of traumatic central cord syndrome. The Spine Journal 10:874-880

19. TAYLOR, A.R., 1951. The mechanism of injury to the spinal cord in the neck without damage to the vertebral column. J Bone Jt Surg 33-B:543-547

20. SCHNEIDER, R.C., SCHEMM, G.W. 1961. Vertebral artery insufficiency in acute and chronic spinal trauma. J Neurosurg 18:348-360 
21. SONG, J., MIZUNO, J., INOUE, T., NAKAGAWA, H. 2006. Clinical evaluation of traumatic central cord syndrome: emphasis on clinical significance of hyperintensity, cord compression, and intramedullary high-signal intensity on magnetic resonance imaging. Surgical Neurology 65:117-123

22. AITO, S., D’ANDREA, M., WERHAGEN, L., FARSETTI, L., CAPELLI, S., BANDINI, B., DI DONNA, V. 2007. Neurological and functional outcome in traumatic central cord syndrome. Spinal Cord 45:292-297

23. DVORAK, M.F., FISHER, C.G., HOEKEMA, J., BOYD, M., NOONAN, V., WING, P.C., KWON, B. 2005. Factors predicting motor recovery and functional outcome after traumatic central cord syndrome. Spine 30:2303-2311

24. CHEN, T., LEE, S., LUI, T., WONG, C., YEH, Y., TZAAN, W., HUNG, S. 1997. Efficacy of surgical treatment in traumatic central cord syndrome. Surg Neurol $48: 435-441$

25. GUEST, J., ELERAKY, M.A., APOSTOLIDES, P.J., DICKMAN, C.A., SONNTAG, V.K. 2002. Traumatic central cord syndrome: results of surgical management. J Neurosurg 97(1 Suppl):25-32

26. URIBE, J., GREEN, B.A., VANNI, S., MOZA, K., GUEST, J.D., LEVI, A.D. 2005. Acute traumatic central cord syndrome - experience using surgical decompression with open-door expansile laminoplasty. Surg Neurol 63:505-510

27. MALIK, S.A., MURPHY, M., CONNOLLY, P., O’BYRNE, J. 2008. Evaluation of morbidity, mortality and outcome in cervical spine injuries in elderly patients. Eur Spine J 17:585-591

28. LENEHAN, B., STREet, J., O’TOOLE, P., SidDiQui, A., POYNTON, A. 2009. Central cord syndrome in Ireland: the effect of age on clinical outcome. Eur Spine J 18:1458-1463

29. ROTH, E.J., LAWLER, M.H., YARKONY, G.M. 1990. Traumatic central cord syndrome: clinical features and functional outcomes. Arch Phys Med Rehabil $71: 18-23$

30. PENROD, L.E., HEDGE, S.K., DITUNNO, J.F. 1990. Age effect on prognosis for functional recovery in acute, traumatic central cord syndrome. Arch Phys Med Rehabil 71:963-968

31. DAI, L., JIA, L. 2005. Central cord injury complicating acute cervical disc herniation in trauma. Spine 25:331-336 
32. THORBURN, W. 1887. Cases of injury to the cervical region of the spinal cord. Brain 9:510-543

33. TAYLOR, A.R., BLACKWOOD, W. 1948. Paraplegia in hyperextension cervical injuries with normal radiographic appearances. J Bone Joint Surg Br 30$\mathrm{B}(2): 245-248$

34. NATHAN, P.W., SMITH, M.C., DEACON, P. 1990. The corticospinal tracts in man. Course and location of fibres at different segmental levels. Brain 113:303324

35. QUENCER, R.M., BUNGE, R.P., EGNOR, M., GREEN, B.A., PUCKETT, W., NAIDICH, T.P., POST, M.J.D., NORENBERG, M. 1992. Acute traumatic central cord syndrome: MRI-pathological correlations. Neuroradiology 34:85-94

36. HARROP, J.S., SHARAN, A., RATCLIFF, J. 2006. Central cord injury: pathophysiology, management, and outcomes. The Spine Journal 6:198S-206S

37. COllignON, F., MARTIN, D., LÉNELlE, J., STEVENAERT, A. 2002. Acute traumatic central cord syndrome: magnetic resonance imaging and clinical observations. J Neurosurg (Spine 1) 96:29-33

38. JIMENEZ, O., MARCILlO, A., LEVI, A.D.O. 2000. A histopathological analysis of the human cervical spinal cord in patients with acute traumatic central cord syndrome. Spinal Cord 38:532-537

39. BENZEL, E.C., HART, B.L., BALL, P.A. 1986. Magnetic resonance imaging for the evaluation of patients with occult cervical spine injuries. J Neurosurg 85:824829

40. KOTHARI, P., FREEMAN, B., GREVITT, M., KERSLAKE, R. 2000. Injury to the spinal cord without radiological abnormality (SCIWORA) in adults $J$ Bone Joint Surg Br 82-B:1034-1037

41. BERNE, J.D., VELHAMOS, G.C., EL-TAWIL, Q. 1999. Value of complete cervical helical computed tomographic scanning in identifying cervical spine injury in the unevaluable blunt trauma patient with multiple images: a prospective study. J Trauma 47(5):896-903

42. GOLDBERG, A., KERSHAH, S. 2009. Advances in imaging of vertebral and spinal cord injury. J Spinal Cord Med 33(2):105-116

43. D’ALISE, M.D., BENZEL, E.C., HART, B.L. 1999. Magnetic resonance imaging evaluation of the cervical spine in the comatose or obtunded trauma patient. $J$ Neurosurg 91(Suppl. 1):54-59 
44. DITUNNO, J.F. 1992. Functional assessment measures in CNS trauma. J Neurotrauma 9:S301-S305

45. DITUNNO, F. YOUNG, W., DONOVAN, W.H., CREASEY, G. 1994. The International Standards Booklet for Neurological and Functional Classification of Spinal Cord Injury. Paraplegia 32:70-80

46. MAYNARD, F.M., BRACKEN, M.B., CREASEY, G., DITUNNO, J.F., DONOVAN, W.H., DUCKER, T.B., GARBER, S.L., MARINO, R.J., STOVER, S.L., TATOR, C.H., WATERS, R.L., WILBERGER, J.E., YOUNG, W. 1997. International standards for neurological and functional classification of spinal cord injury. Spinal Cord 35:266-274

47. KIRSHBLUM, S.C., BURNS, S.P., BIERING-SORENSEN, F., DONOVAN, W., GRAVES, D.E., JHA, A., JOHANSEN, M., JONES, L., KRASSIOUKOV, A., MULCAHEY, M.J., SCHMIDT-READ, M., WARING, W. 2011. International standards for neurological classification of spinal cord injury (Revised 2011). $J$ Spinal Cord Med 34(6):535-546

48. FRANKEL, H.L., HANCOCK, D.O., HYSLOP, G. 1969. The value of postural reduction in the initial management of closed injuries of the spine with paraplegia and tetraplegia. Paraplegia 7(3):179-192

49. TOW, A.P., KONG, K.H. 1998. Central cord syndrome: functional outcome after rehabilitation. Spinal Cord 36:156-160

50. SONG, J., MIZUNO, J., NAKAGAWA, H., INOUE, T. 2005. Surgery for acute subaxial traumatic central cord syndrome without fracture or dislocation. Journal of Clinical Neuroscience 12(4):438-443

51. AARABI, B., KOLTZ, M., IBRAHIMI, D. 2008. Hyperextension cervical cord injuries and traumatic central cord syndrome. Neurosurg Focus 25:1-8

52. FONG, W., EISMONT, F.J. 2007. Controversies in the treatment of central cord injuries. Semin Spine Surg 19:260-271

53. CHEN, L., YANG, H., YANG, T., XU, Y., BAO, Z., TANG, T. 2009. Effectiveness of surgical treatment for traumatic central cord syndrome. $J$ Neurosurg Spine 10:3-8

54. STEVENS, E.A., POWERS, A.K., BRANCH, C.L. 2009. The role of surgery in traumatic central cord syndrome. Neurosurgery Quarterly 19(4):222-227 
55. URIBE, J., GREE, B.A., VANNI, S., MOZA, K., GUEST, J.D., LEVI, A.D. 2005. Acute traumatic cord syndrome - experience using surgical decompression with open-door expansile cervical laminosplasty. Spine 63:505-510

56. LENEHEN, B., FISHER, C.G., VACCARO, A., FEHLINGS, M., AARABI, B., DVORAK, M.F. 2010. The urgency of surgical decompression in acute central cord injuries with spondylosis and without instability. Spine 35(21-S)S180-S186

57. KIM, I. 2011. Acute traumatic central cord syndrome: early decompression or not? Korean J Spine 8(1):45-51

58. YADLA, S., KLIMO, P., HARROP, J.S. 2010. Traumatic central cord syndrome: etiology, management, and outcomes. Top Spinal Cord Inj Rehabil 15(3):73-84

59. RASLAN, A.M., NEMECEK, A.N. 2012. Controversies in the surgical management of spinal cord injuries. Neurology Research International $10.1155 / 2012 / 417834$ ( 6 pages)

60. ANDERSON, D.G., SAYADIPOUR, A., LIMTHONGKUL, W., MARTIN, N.D., VACCARO, A., HARROP, J.S. 2012. Am J Orthop 41(8):104-108

61. MIRANDA, P., GOMEZ, P., ALDEY, R. 2008. Acute traumatic central cord syndrome: analysis of clinical and radiological correlations. J Neurosurg Sci $52: 107-112$

62. BRODKEY, J.S., MILLER, C.F., HARMODY, R.M. 1980. The syndrome of acute central cervical spinal cord injury revisited. Surg Neurol 14:251-257

63. CHEN, T.Y., DICKMAN, C.A., ELERAKY, M. 1998. The role of decompression for acute incomplete cervical spinal cord injury in cervical spondylosis. Spine 23:398-403

64. FURLAN, J.C., NOONAN, V., SINGH, A., FEHLINGS, M.G. 2001. Assessment of impairment in patients with acute traumatic spinal cord injury: a systematic review of the literature

65. TURNER-STOKES, L., NYEIN, K., TURNER-STOKES, T. 1999. The UK FIM+FAM: development and evaluation. Clin Rehabil 13:277-287 
Part D: Appendix

ASIA Standard Neurological Classification of Spinal Cord Injury

FIM scale and guidelines

Data Sheets

Human Research Ethics Committee Approval Letter

Dissertations Committee Approval Letter

MMed Guidelines

Dissertation Guidelines

European Spine Journal Guidelines 


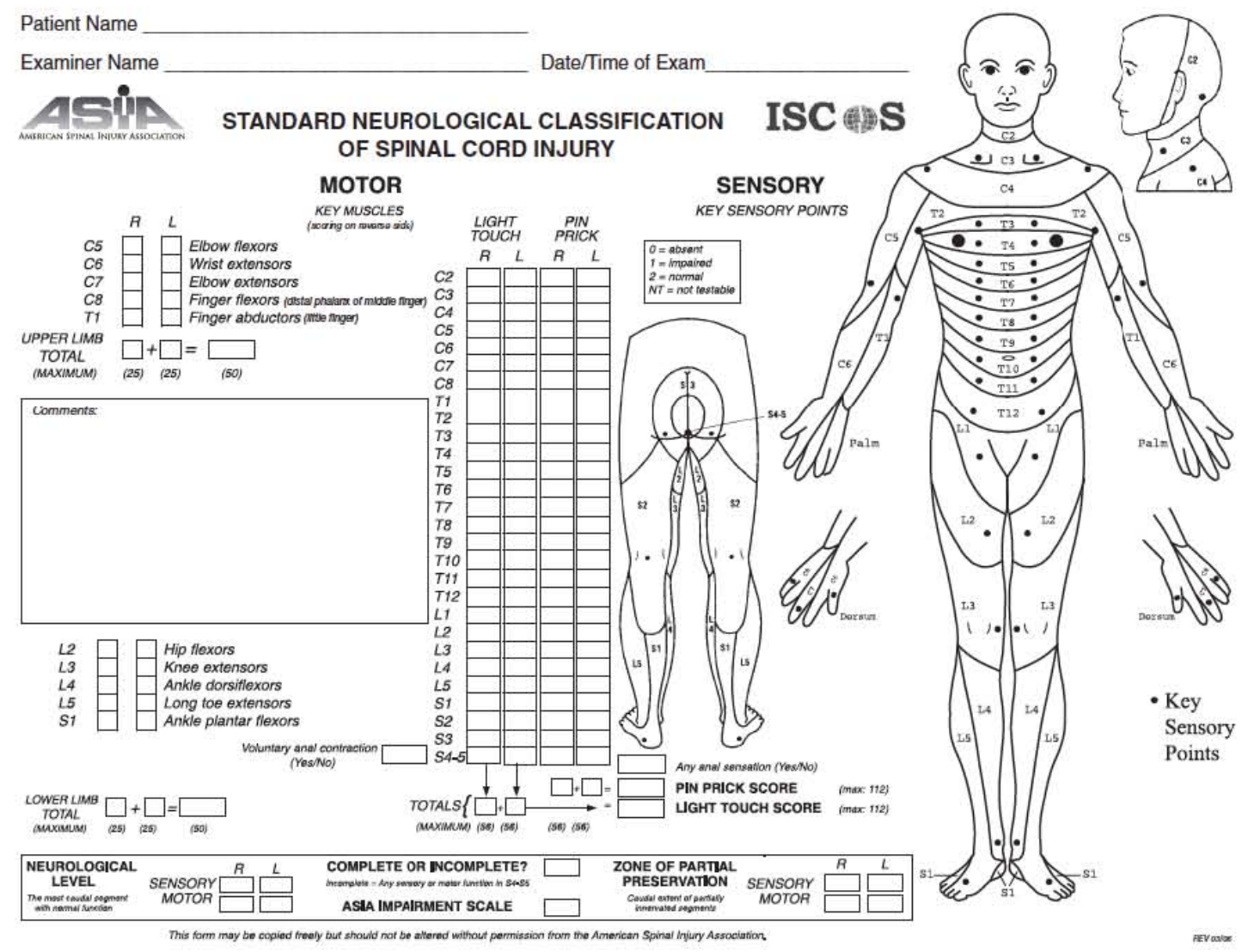

MUSCLE GRADING

0 total paralysis

1 palpable or visible contraction

2 active movement, full range of motion, gravity eliminated

3 active movement, full range of motion, against gravity

4 active movement, full range of motion, against gravity and provides some resistance

5 active movement, full range of motion, against gravity and provides normal resistance

$5^{*}$ muscle ablo to exert, in examiner's judgement, sufficient resistance to be considered normal if identifiable inhibiting factors were not present

NT not testable. Patient unable to reliably exert effort or muscle unavailable for testing due to factors such as immobilization, pain on effort or contracture.
ASIA IMPAIRMENT SCALE

$\square \quad \mathbf{A}=$ Complete: No motor or sensory function is preserved in the sacral segments S4-S5.

$\square \quad \mathbf{B}=$ Incomplete: Sensory but not moto function is preserved below the neurological level and includes the sacral segments S4-S5.

$\square \quad C=$ Incomplete: Motor function is preserved below the neurological level, and more than half of key muscles below the neurological level have a muscle grade less than 3 .

D $=$ Incomplete: Motor function is preserved below the neurological level, and at least half of key muscles below the neurological level have a muscle grade of 3 or more.

$\square \quad \mathbf{E}=$ Normal: Motor and sensory funetion are normal.

CLINICAL SYNDROMES (OPTIONAL)

$\square$ Central Cord

$\square$ Brown-Sequard

$\square$ Anterior Cord

$\square$ Conus Medullaris

$\square$ Cauda Equina

\section{STEPS IN CLASSIFICATION}

The following order is recommended in determining the classification of individuals with $\mathrm{SCl}$.

1. Determine sensory levels for right and left sides:

2. Determine motor levels for right and left sides. Note: in negions where there is no myotome to test, the motor level is presumed to be the same as the sensory level.

3. Determine the single neurological level.

This is the lowest segment where motor and sensory function is normal on both sides, and is the most cephalad of the sensory and motor levels determined in steps $I$ and 2 .

4. Determine whether the injury is Complete or Incomplete (sacral sparing).

If woluntary anal contraction $=$ No AND all S4-5 sensory scores $=0$ $A N D$ any anal sensation $=$ No, then injury is COMPIETE Otherwise injury is incomplete.

5. Determine ASIA Impairment Scale (AIS) Grade: Is injury Camplete? If YES, AIS=A Rocord ZPP NO (For ZPP record lowest dermatime of myotome of Is injury motor incomplete? If NO, AIS=B YES (Yosevoluntary anal contraction OR motor evel on a given side)

Are at least half of the key muscles below the (single) neurological level graded 3 or better?

$$
\text { No \ YES | }
$$

If sensation and motor function is normal in all segments, AIS =F Note: AIS $E$ is used in follow up testing when an individual with a documented $S C l$ has recovered normal function. If at initial terting no deficits are found, the individual is nearologically intact; the ASIA Impaiment Scale does not apply 


\section{FIM scale}

\section{Self-care}

1. Eating

2. Grooming

3. Bathing/showering

4. Dressing upper body

5. Dressing lower body

6. Toileting

7. Swallowing

\section{Sphincters}

1. Bladder management

2. Bowel management

\section{Mobility}

1. Transfers: bed/chair/wheelchair

2. Transfers: toilet

3. Transfers: bathtub/shower

4. Transfers: car

5. Locomotion: walking/wheelchair

6. Locomotion: stairs

7. Community mobility

\section{Communication}

1. Expression

2. Comprehension

3. Reading

4. Writing

5. Speech intelligibility

\section{Psychosocial}

1. Social interaction

2. Emotional status 
3. Adjustment to limitations

4. Use of leisure time

\section{Cognition}

1. Problem solving

2. Memory

3. Orientation

4. Concentration

5. Safety awareness

\section{Seven levels for each item}

Level Description

7 - Complete independence Fully independent

6 - Modified independence Requiring the use of a device but no physical help

5 - Supervision $\quad$ Requiring only standby assistance or verbal prompting or help with set-up

4 - Minimal assistance Requiring incidental hands-on help only (subject performs $>75 \%$ of the task)

3 - Moderate assistance $\quad$ Subject still performs $50-75 \%$ of the task

2 - Maximal assistance $\quad$ Subject provides less than half of the effort (25-49\%)

1 - Total assistance Subject contributes $<25 \%$ of the effort or is unable to do the task

\section{Scoring principles}

- Function is assessed on the basis of direct observation

- Admission scoring is done within 10 days of admission

- Discharge scoring is done during the last week before discharge

- Scoring is done by a multi-disciplinary team member

- The subject is scored on what they actually do on a day-to-day basis, not on what they could do

- Do not leave any score blank

- Score 1 if the subject does not perform the activity at all, or if no information is available 
- If function is variable, use the lower score

\section{Central Cord Data Collection Form}

Patient:

Folder no:

DoB:

Audit no:

\section{Epidemiology}

Age

Gender

Mode of injury

Interval from injury to admission

Pre-existing myelopathy

Precious cervical spine surgery

Alcohol involvement

Smoker

Employed

years

Male / Female

Minor / Major fall

High Speed Accident

Assault

Other -

Yes / No

Yes / No

Yes / No

Yes / No

Yes / No

\section{Pathology}

Vertebral level

Level of neurological injury

Extent of neurological injury

Grade of neurological injury

Disc prolapse

Osteophyte

Canal diameter (level of injury)

MRI (T2 hyperintensity)

Underlying pathology

Level of underlying pathology

Soft tissue injury

Progression (spontaneous)

Progression (following surgery)

Recovery (spontaneous)

Recovery (following surgery)

C

Complete / Incomplete

Frankel A B C D E

ASIA A B C D E

Yes / No

Yes / No

$\mathrm{mm}$

Yes / No

OPLL / Autofusion / Stenosis / Surgery

$\mathrm{C}$

Yes / No

Yes / No

Yes / No

Yes / No

Yes / No

days
Anterior / Posterior
C
Yes / No

Yes / No

Yes / No

Yes / No

Frankel A B C D E

ASIA A B C D E days

Yes / No

Yes / No

Yes / No 


\begin{tabular}{|c|c|c|c|c|c|c|c|c|c|c|c|}
\hline 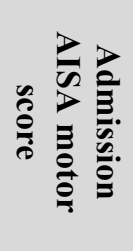 & $\begin{array}{l}\frac{3}{0} \\
\frac{0}{0} \\
\overrightarrow{0} \\
\frac{1}{2} \\
\frac{0}{\bar{\lambda}}\end{array}$ & 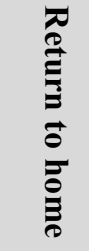 & 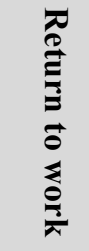 & 这 & 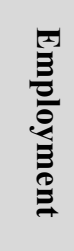 & 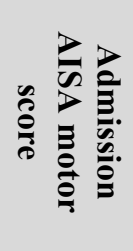 & 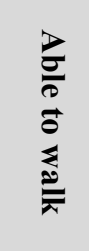 & 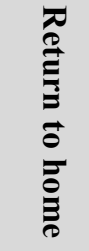 & 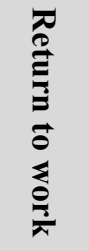 & $\frac{3}{\frac{3}{2}}$ & 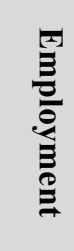 \\
\hline 0 & No & No & No & Yes & No & 60 & Yes & Yes & No & No & Yes \\
\hline 0 & No & No & No & No & No & 60 & Yes & No & No & No & Yes \\
\hline 0 & Yes & Yes & No & No & No & 61 & No & No & No & No & No \\
\hline 0 & No & No & No & No & Yes & 63 & Yes & Yes & No & No & No \\
\hline 0 & No & No & No & No & Yes & 64 & Yes & Yes & No & No & Yes \\
\hline 3 & No & No & No & No & No & 68 & Yes & No & No & No & Yes \\
\hline 3 & No & No & No & No & No & 70 & No & No & No & No & Yes \\
\hline 4 & No & No & No & No & Yes & 70 & Yes & No & No & No & Yes \\
\hline 4 & No & No & No & No & Yes & 73 & No & No & No & No & No \\
\hline 6 & No & No & No & No & Yes & 73 & Yes & Yes & No & No & No \\
\hline 10 & No & No & No & No & No & 74 & No & No & No & No & Yes \\
\hline 14 & No & No & No & No & No & 75 & Yes & Yes & No & No & Yes \\
\hline 16 & Yes & No & No & No & No & 75 & Yes & Yes & No & No & Yes \\
\hline 21 & Yes & Yes & No & No & Yes & 78 & Yes & No & No & No & No \\
\hline 22 & No & No & No & No & No & 80 & Yes & Yes & No & No & No \\
\hline 23 & No & No & No & No & Yes & 82 & Yes & No & No & No & Yes \\
\hline 25 & No & Yes & No & No & No & 84 & Yes & Yes & No & No & No \\
\hline 27 & No & No & No & No & Yes & 86 & Yes & Yes & No & No & No \\
\hline 30 & No & No & No & No & No & 90 & Yes & Yes & Yes & No & Yes \\
\hline 32 & Yes & No & No & No & Yes & 95 & Yes & Yes & No & No & No \\
\hline 32 & Yes & No & No & No & Yes & 95 & Yes & Yes & No & No & Yes \\
\hline 44 & No & No & No & No & Yes & 95 & Yes & Yes & Yes & No & Yes \\
\hline 46 & No & No & No & No & No & 96 & Yes & Yes & Yes & No & Yes \\
\hline 48 & No & No & No & No & Yes & 100 & Yes & Yes & Yes & No & Yes \\
\hline 52 & No & No & No & No & No & & & & & & \\
\hline 57 & Yes & Yes & No & No & Yes & & & & & & \\
\hline 59 & No & No & No & No & No & & & & & & \\
\hline
\end{tabular}




\begin{tabular}{|lllll|lllll|}
\hline & & & & & & \\
\hline
\end{tabular}




\begin{tabular}{|c|c|c|c|c|c|c|c|c|c|c|c|c|c|c|c|c|}
\hline 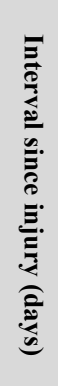 & 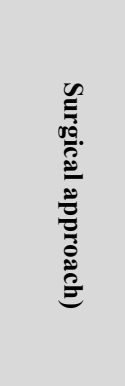 & $\frac{2}{2}$ & 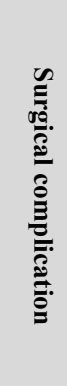 & 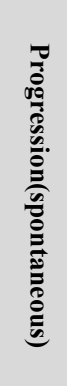 & 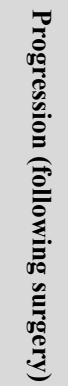 & 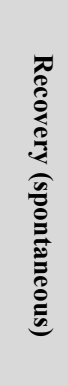 & 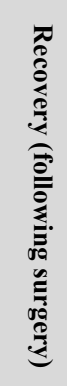 & 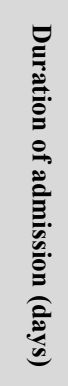 & 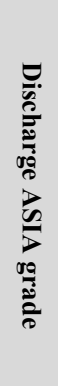 & 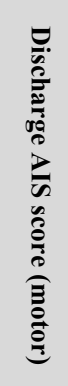 & 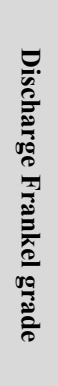 & 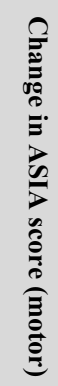 & 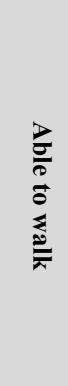 & 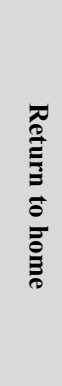 & 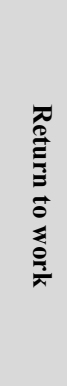 & $\frac{3}{3}$ \\
\hline $\mathrm{N} / \mathrm{a}$ & $\mathrm{N} / \mathrm{a}$ & N/a & N/a & No & N/a & Yes & N/a & 10 & $\mathrm{E}$ & 100 & $\mathrm{E}$ & 87 & Yes & Yes & No & No \\
\hline $\mathrm{N} / \mathrm{a}$ & N/a & $\mathrm{N} / \mathrm{a}$ & $\mathrm{N} / \mathrm{a}$ & No & $\mathrm{N} / \mathrm{a}$ & Yes & N/a & 55 & $\mathrm{D}$ & 49 & $\mathrm{C}$ & 35 & No & No & No & No \\
\hline 3 & Anterior & $\mathrm{C} 3 / 4$ & No & No & No & No & Yes & 14 & $\mathrm{D}$ & 88 & $\mathrm{D}$ & 71 & Yes & Yes & No & No \\
\hline 108 & Posterior & C3-6 & No & No & No & No & No & 22 & $\mathrm{D}$ & 70 & $\mathrm{D}$ & 53 & No & No & No & No \\
\hline $\mathrm{N} / \mathrm{a}$ & $\mathrm{N} / \mathrm{a}$ & $\mathrm{N} / \mathrm{a}$ & $\mathrm{N} / \mathrm{a}$ & No & $\mathrm{N} / \mathrm{a}$ & Yes & $\mathrm{N} / \mathrm{a}$ & 6 & $\mathrm{D}$ & 74 & $\mathrm{D}$ & 55 & No & No & No & No \\
\hline $\mathrm{N} / \mathrm{a}$ & $\mathrm{N} / \mathrm{a}$ & $\mathrm{N} / \mathrm{a}$ & $\mathrm{N} / \mathrm{a}$ & No & $\mathrm{N} / \mathrm{a}$ & Yes & $\mathrm{N} / \mathrm{a}$ & 5 & $\mathrm{E}$ & 100 & $\mathrm{E}$ & 80 & Yes & Yes & Yes & No \\
\hline 27 & Posterior & C4-6 & No & No & No & Yes & Yes & 32 & $\mathrm{D}$ & 63 & $\mathrm{D}$ & 42 & Yes & No & No & No \\
\hline 10 & Posterior & $\mathrm{C} 4-5$ & No & No & No & No & Yes & 13 & $\mathrm{D}$ & 50 & $\mathrm{D}$ & 28 & No & No & No & No \\
\hline 26 & Anterior & $\mathrm{C} 3 / 4$ & No & No & No & Yes & No & 29 & $\mathrm{C}$ & 16 & $\mathrm{C}$ & -8 & No & No & No & No \\
\hline $\mathrm{N} / \mathrm{a}$ & $\mathrm{N} / \mathrm{a}$ & $\mathrm{N} / \mathrm{a}$ & $\mathrm{N} / \mathrm{a}$ & No & $\mathrm{N} / \mathrm{a}$ & No & $\mathrm{N} / \mathrm{a}$ & 3 & A & 0 & A & -24 & No & No & No & Yes \\
\hline 16 & Posterior & C4-6 & No & No & No & Yes & No & 15 & $\mathrm{C}$ & 42 & $\mathrm{C}$ & 16 & No & No & No & No \\
\hline 6 & Anterior & $\mathrm{C} 3 / 4$ & No & No & No & No & Yes & 17 & $\mathrm{D}$ & 91 & $\mathrm{D}$ & 64 & Yes & Yes & No & No \\
\hline 4 & Anterior & $\mathrm{C}$ & No & No & No & No & Yes & 26 & B & 0 & B & -28 & No & No & No & No \\
\hline $\mathrm{N} / \mathrm{a}$ & $\mathrm{N} / \mathrm{a}$ & $\mathrm{N} / \mathrm{a}$ & $\mathrm{N} / \mathrm{a}$ & No & $\mathrm{N} / \mathrm{a}$ & Yes & $\mathrm{N} / \mathrm{a}$ & 14 & $\mathrm{D}$ & 73 & $\mathrm{D}$ & 44 & Yes & No & No & No \\
\hline 106 & Posterior & C3-6 & No & No & No & Yes & Yes & 27 & $\mathrm{D}$ & 88 & $\mathrm{D}$ & 58 & Yes & No & No & No \\
\hline $\mathrm{N} / \mathrm{a}$ & $\mathrm{N} / \mathrm{a}$ & $\mathrm{N} / \mathrm{a}$ & $\mathrm{N} / \mathrm{a}$ & No & $\mathrm{N} / \mathrm{a}$ & No & $\mathrm{N} / \mathrm{a}$ & 49 & $\mathrm{C}$ & 46 & $\mathrm{C}$ & 15 & No & No & No & No \\
\hline 17 & Posterior & C3-6 & No & No & No & No & No & 15 & $\mathrm{D}$ & 60 & $\mathrm{D}$ & 29 & No & No & No & No \\
\hline $\mathrm{N} / \mathrm{a}$ & $\mathrm{N} / \mathrm{a}$ & $\mathrm{N} / \mathrm{a}$ & $\mathrm{N} / \mathrm{a}$ & No & $\mathrm{N} / \mathrm{a}$ & Yes & $\mathrm{N} / \mathrm{a}$ & 2 & $\mathrm{D}$ & 95 & $\mathrm{D}$ & 60 & Yes & Yes & No & No \\
\hline 8 & Posterior & C3-4 & No & No & No & No & No & 21 & $\mathrm{C}$ & 48 & $\mathrm{C}$ & 13 & No & No & No & No \\
\hline 39 & Posterior & C3-6 & No & No & No & No & No & 178 & A & 6 & A & -30 & No & No & No & No \\
\hline N/a & $\mathrm{N} / \mathrm{a}$ & $\mathrm{N} / \mathrm{a}$ & $\mathrm{N} / \mathrm{a}$ & No & $\mathrm{N} / \mathrm{a}$ & Yes & $\mathrm{N} / \mathrm{a}$ & 70 & $\mathrm{D}$ & 83 & $\mathrm{D}$ & 45 & Yes & No & No & No \\
\hline 6 & Anterior & $\mathrm{C} 5 / 6$ & No & No & No & No & No & 44 & A & 3 & A & -37 & No & No & No & No \\
\hline N/a & $\mathrm{N} / \mathrm{a}$ & $\mathrm{N} / \mathrm{a}$ & $\mathrm{N} / \mathrm{a}$ & Yes & $\mathrm{N} / \mathrm{a}$ & Yes & $\mathrm{N} / \mathrm{a}$ & 23 & $\mathrm{D}$ & 71 & $\mathrm{D}$ & 30 & Yes & No & No & No \\
\hline 12 & Posterior & C3-6 & No & No & No & No & Yes & 28 & $\mathrm{D}$ & 71 & $\mathrm{D}$ & 30 & Yes & No & No & No \\
\hline 27 & Posterior & $\mathrm{C} 4-5$ & Yes & No & No & No & Yes & 39 & $\mathrm{D}$ & 86 & $\mathrm{C}$ & 44 & No & No & No & No \\
\hline 8 & Anterior & $\mathrm{C} 3 / 4$ & No & No & No & No & No & 50 & A & 0 & A & -42 & No & No & No & No \\
\hline $\mathrm{N} / \mathrm{a}$ & $\mathrm{N} / \mathrm{a}$ & $\mathrm{N} / \mathrm{a}$ & $\mathrm{N} / \mathrm{a}$ & No & $\mathrm{N} / \mathrm{a}$ & Yes & $\mathrm{N} / \mathrm{a}$ & 6 & $\mathrm{D}$ & 95 & $\mathrm{D}$ & 52 & Yes & Yes & No & No \\
\hline 6 & Posterior & C3-5 & No & No & No & No & Yes & 15 & $\mathrm{C}$ & 48 & $\mathrm{C}$ & 5 & No & Yes & No & No \\
\hline 11 & Anterior & $\mathrm{C} 5 / 6$ & No & No & No & No & No & 16 & $\mathrm{D}$ & 94 & $\mathrm{D}$ & 51 & Yes & Yes & No & No \\
\hline $\mathrm{N} / \mathrm{a}$ & $\mathrm{N} / \mathrm{a}$ & $\mathrm{N} / \mathrm{a}$ & $\mathrm{N} / \mathrm{a}$ & No & $\mathrm{N} / \mathrm{a}$ & Yes & $\mathrm{N} / \mathrm{a}$ & 7 & $\mathrm{E}$ & 100 & $\mathrm{E}$ & 55 & Yes & Yes & Yes & No \\
\hline 12 & Posterior & C4-6 & No & No & No & No & No & 22 & A & 3 & A & -43 & No & No & No & No \\
\hline 8 & Posterior & C3-5 & No & No & No & No & Yes & 47 & $\mathrm{C}$ & 27 & $\mathrm{C}$ & -20 & No & No & No & No \\
\hline 15 & Posterior & C3-6 & No & No & No & No & No & 38 & B & 4 & B & -43 & No & No & No & No \\
\hline N/a & $\mathrm{N} / \mathrm{a}$ & $\mathrm{N} / \mathrm{a}$ & $\mathrm{N} / \mathrm{a}$ & No & $\mathrm{N} / \mathrm{a}$ & Yes & $\mathrm{N} / \mathrm{a}$ & 16 & $\mathrm{D}$ & 71 & $\mathrm{D}$ & 23 & Yes & Yes & No & No \\
\hline 1 & Anterior & $\mathrm{C} 5 / 6$ & No & No & No & No & Yes & 12 & $\mathrm{D}$ & 90 & $\mathrm{D}$ & 38 & Yes & Yes & No & No \\
\hline 17 & Posterior & $\mathrm{C} 0-2$ & No & No & No & Yes & Yes & 52 & $\mathrm{D}$ & 70 & $\mathrm{D}$ & 17 & No & No & No & No \\
\hline N/a & $\mathrm{N} / \mathrm{a}$ & N/a & $\mathrm{N} / \mathrm{a}$ & No & $\mathrm{N} / \mathrm{a}$ & Yes & $\mathrm{N} / \mathrm{a}$ & 17 & $\mathrm{D}$ & 75 & $\mathrm{D}$ & 22 & Yes & No & No & No \\
\hline 8 & Posterior & C3-6 & No & No & No & Yes & Yes & 18 & $\mathrm{D}$ & 72 & $\mathrm{D}$ & 18 & No & No & No & No \\
\hline 2 & Anterior & $\mathrm{C} 5 / 6$ & No & No & No & No & Yes & 12 & $\mathrm{D}$ & 90 & $\mathrm{D}$ & 36 & Yes & Yes & No & No \\
\hline $\mathrm{N} / \mathrm{a}$ & $\mathrm{N} / \mathrm{a}$ & $\mathrm{N} / \mathrm{a}$ & $\mathrm{N} / \mathrm{a}$ & No & $\mathrm{N} / \mathrm{a}$ & Yes & $\mathrm{N} / \mathrm{a}$ & 21 & $\mathrm{E}$ & 100 & E & 45 & Yes & Yes & No & No \\
\hline
\end{tabular}




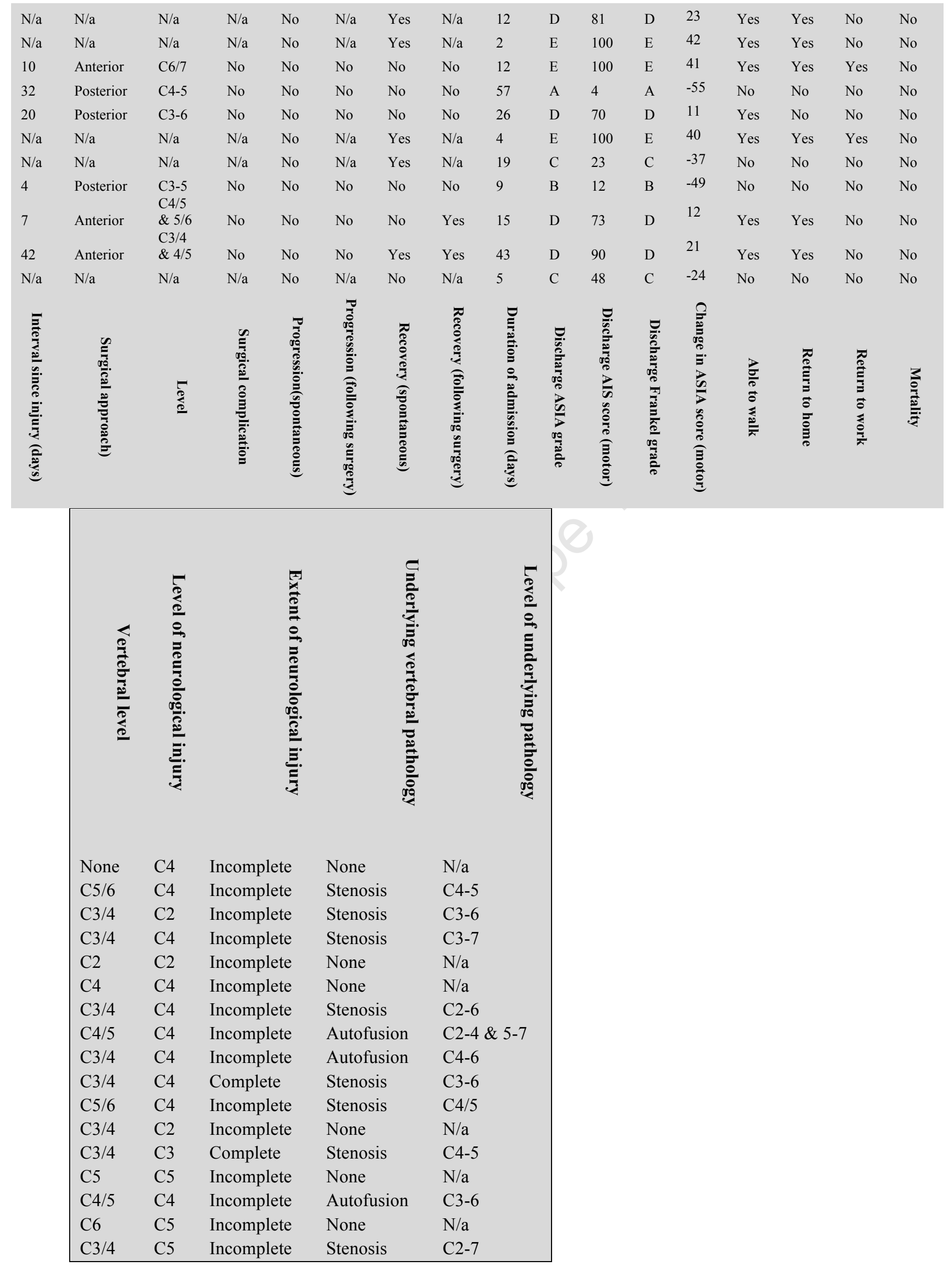




\begin{tabular}{|c|c|c|c|c|c|}
\hline None & $\mathrm{C} 5$ & Incomplete & None & $\mathrm{N} / \mathrm{a}$ & \\
\hline $\mathrm{C} 3 / 4$ & $\mathrm{C} 4$ & Incomplete & Stenosis & C3-6 & \\
\hline $\mathrm{C} 2$ & $\mathrm{C} 2$ & Complete & Stenosis & $\mathrm{C} 2-7$ & \\
\hline C5 & $\mathrm{C} 5$ & Incomplete & None & $\mathrm{N} / \mathrm{a}$ & \\
\hline $\mathrm{C} 5 / 6$ & $\mathrm{C} 3$ & Complete & None & $\mathrm{N} / \mathrm{a}$ & \\
\hline $\mathrm{C} 5 / 6$ & $\mathrm{C} 5$ & Incomplete & None & $\mathrm{N} / \mathrm{a}$ & \\
\hline $\mathrm{C} 3 / 4$ & $\mathrm{C} 4$ & Incomplete & Stenosis & C3-4 & \\
\hline C3-6 & $\mathrm{C} 4$ & Incomplete & Stenosis & C3-6 & \\
\hline $\mathrm{C} 3 / 4$ & $\mathrm{C} 3$ & Complete & Stenosis & $\mathrm{C} 5-6$ & \\
\hline $\mathrm{C} 3 / 4$ & $\mathrm{C} 4$ & Incomplete & Autofusion & $\mathrm{C} 5-6$ & \\
\hline $\mathrm{C} 3 / 4$ & $\mathrm{C} 4$ & Incomplete & Autofusion & C5-6 & \\
\hline C5/6 & $\mathrm{C} 5$ & Incomplete & None & $\mathrm{N} / \mathrm{a}$ & \\
\hline $\mathrm{C} 3 / 4$ & $\mathrm{C} 5$ & Incomplete & None & $\mathrm{N} / \mathrm{a}$ & \\
\hline $\mathrm{C} 3 / 4$ & $\mathrm{C} 4$ & Complete & Stenosis & C3-5 & \\
\hline C4 & $\mathrm{C} 3$ & Complete & None & $\mathrm{N} / \mathrm{a}$ & \\
\hline C3-6 & $\mathrm{C} 4$ & Incomplete & Stenosis & C3-6 & \\
\hline C3-5 & $\mathrm{C} 2$ & Incomplete & None & $\mathrm{N} / \mathrm{a}$ & \\
\hline $\mathrm{C} 5 / 6$ & $\mathrm{C} 5$ & Incomplete & None & $\mathrm{N} / \mathrm{a}$ & \\
\hline $\mathrm{C} 1$ & $\mathrm{C} 3$ & Incomplete & Autofusion & $\mathrm{C} 0-1$ & \\
\hline $\mathrm{C} 4 / 5$ & $\mathrm{C} 3$ & Incomplete & None & $\mathrm{N} / \mathrm{a}$ & \\
\hline C3-6 & $\mathrm{C} 4$ & Incomplete & Stenosis & C3-6 & \\
\hline $\mathrm{C} 5 / 6$ & $\mathrm{C} 5$ & Incomplete & None & $\mathrm{N} / \mathrm{a}$ & \\
\hline $\mathrm{C} 1$ & $\mathrm{C} 4$ & Incomplete & None & $\mathrm{N} / \mathrm{a}$ & \\
\hline $\mathrm{C} 4 / 5$ & $\mathrm{C} 4$ & Incomplete & None & $\mathrm{N} / \mathrm{a}$ & \\
\hline None & $\mathrm{C} 4$ & Incomplete & None & $\mathrm{N} / \mathrm{a}$ & \\
\hline $\mathrm{C} 6 / 7$ & & Incomplete & None & N/a & \\
\hline $\mathrm{C} 4 / 5$ & $\mathrm{C} 4$ & Complete & None & $\mathrm{N} / \mathrm{a}$ & \\
\hline C3-5 & $\mathrm{C} 4$ & Incomplete & Stenosis & C3-6 & \\
\hline None & $\mathrm{C} 4$ & Incomplete & None & $\mathrm{N} / \mathrm{a}$ & \\
\hline $\mathrm{C} 5 / 6$ & $\mathrm{C} 5$ & Incomplete & Stenosis & C6-7 & \\
\hline $\mathrm{C} 4 / 5$ & $\mathrm{C} 5$ & Incomplete & OPLL & $\mathrm{C} 2-7$ & \\
\hline $\mathrm{C} 5 / 6$ & $\mathrm{C} 5$ & Incomplete & Stenosis & C3-5 & \\
\hline C3-5 & $\mathrm{C} 4$ & Incomplete & Stenosis & C3-5 & \\
\hline $\mathrm{C} 3 / 4$ & $\mathrm{C} 4$ & Incomplete & None & $\mathrm{N} / \mathrm{a}$ & \\
\hline $\begin{array}{l}\frac{a}{2} \\
\frac{0}{2} \\
\frac{0}{0} \\
\stackrel{0}{0} \\
\frac{9}{2} \\
0\end{array}$ & 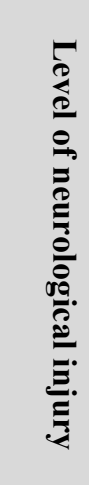 & 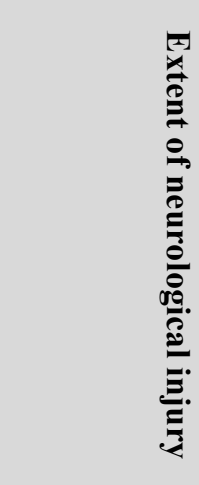 & 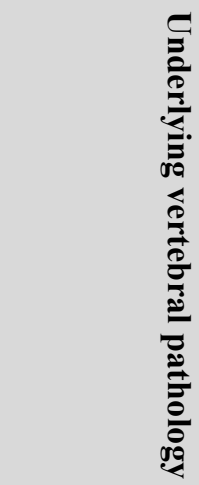 & & 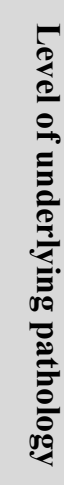 \\
\hline
\end{tabular}




\begin{tabular}{|c|c|c|c|c|c|c|c|c|c|}
\hline 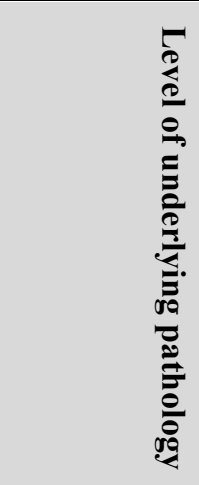 & 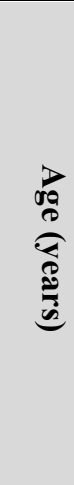 & 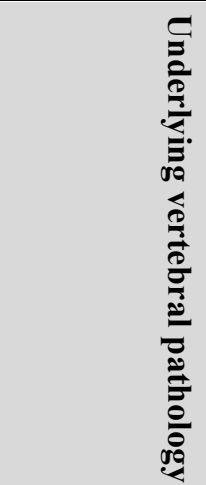 & 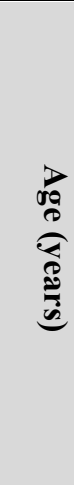 & 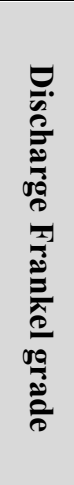 & 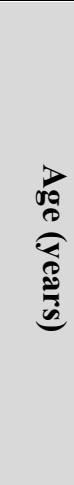 & 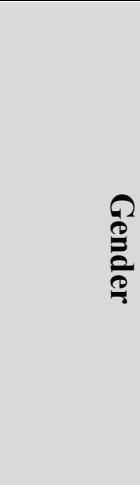 & 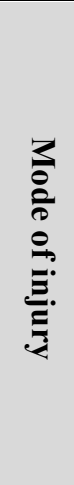 & 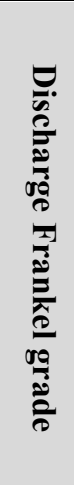 & 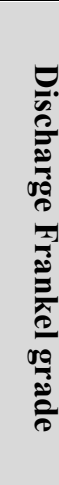 \\
\hline $\mathrm{N} / \mathrm{a}$ & 13 & None & 13 & $\mathrm{~F}$ & 31 & Male & $\mathrm{H}$ & F & E \\
\hline $\mathrm{N} / \mathrm{a}$ & 14 & None & 14 & $\mathrm{~F}$ & 13 & Female & $\mathrm{H}$ & $\mathrm{F}$ & E \\
\hline $\mathrm{N} / \mathrm{a}$ & 17 & None & 17 & $\mathrm{~F}$ & 14 & Male & $\mathrm{H}$ & F & D \\
\hline $\mathrm{N} / \mathrm{a}$ & 17 & None & 17 & $\mathrm{~F}$ & 17 & Male & $\mathrm{H}$ & $\mathrm{F}$ & E \\
\hline $\mathrm{N} / \mathrm{a}$ & 19 & None & 19 & $\mathrm{~N}$ & 17 & Male & $\mathrm{H}$ & $\mathrm{N}$ & E \\
\hline $\mathrm{N} / \mathrm{a}$ & 20 & None & 20 & $\mathrm{~F}$ & 19 & Male & $\mathrm{H}$ & $\mathrm{F}$ & A \\
\hline $\mathrm{N} / \mathrm{a}$ & 21 & None & 21 & $\mathrm{~F}$ & 20 & Female & $\mathrm{H}$ & $\mathrm{F}$ & D \\
\hline $\mathrm{N} / \mathrm{a}$ & 22 & None & 22 & $\mathrm{~F}$ & 21 & Male & $\mathrm{H}$ & $\mathrm{F}$ & D \\
\hline $\mathrm{N} / \mathrm{a}$ & 24 & None & 24 & $\mathrm{~F}$ & 22 & Male & $\mathrm{H}$ & $\mathrm{F}$ & D \\
\hline $\mathrm{N} / \mathrm{a}$ & 24 & None & 24 & $\mathrm{~F}$ & 24 & Male & $\mathrm{H}$ & $\mathrm{F}$ & E \\
\hline $\mathrm{N} / \mathrm{a}$ & 26 & None & 26 & $\mathrm{~N}$ & 24 & Male & $\mathrm{H}$ & $\mathrm{N}$ & D \\
\hline $\mathrm{N} / \mathrm{a}$ & 27 & None & 27 & $\mathrm{~F}$ & 26 & Male & $\mathrm{H}$ & $\mathrm{F}$ & $\mathrm{C}$ \\
\hline $\mathrm{N} / \mathrm{a}$ & 28 & None & 28 & $\mathrm{~F}$ & 27 & Male & $\mathrm{H}$ & $\mathrm{F}$ & $\mathrm{D}$ \\
\hline C4-5 & 29 & Stenosis & 29 & $\mathrm{~N}$ & 28 & Male & $\mathrm{H}$ & $\mathrm{N}$ & $\mathrm{E}$ \\
\hline $\mathrm{N} / \mathrm{a}$ & 30 & None & 30 & $\mathrm{~F}$ & 29 & Male & $\mathrm{H}$ & $\mathrm{F}$ & $\mathrm{C}$ \\
\hline $\mathrm{N} / \mathrm{a}$ & 31 & None & 31 & $\mathrm{~F}$ & 30 & Male & $\mathrm{H}$ & $\mathrm{F}$ & E \\
\hline $\mathrm{N} / \mathrm{a}$ & 31 & None & 31 & $\mathrm{~N}$ & 31 & Male & $\mathrm{H}$ & $\mathrm{N}$ & $\mathrm{C}$ \\
\hline N/a & 35 & None & 35 & F & 35 & Male & $\mathrm{H}$ & $\mathrm{F}$ & D \\
\hline C3-5 & 35 & Stenosis & 35 & $\mathrm{~F}$ & 35 & Male & $\mathrm{H}$ & F & D \\
\hline $\mathrm{N} / \mathrm{a}$ & 36 & None & 36 & $\mathrm{~F}$ & 36 & Female & $\mathrm{H}$ & $\mathrm{F}$ & $\mathrm{D}$ \\
\hline C4-5 & 38 & Stenosis & 38 & $\mathrm{~N}$ & 38 & Male & $\mathrm{H}$ & $\mathrm{N}$ & B \\
\hline C3-6 & 40 & Stenosis & 40 & $\mathrm{~N}$ & 40 & Male & $\mathrm{H}$ & $\mathrm{N}$ & $\mathrm{C}$ \\
\hline C3-6 & 41 & Stenosis & 41 & F & 41 & Male & $\mathrm{H}$ & $\mathrm{F}$ & $\mathrm{D}$ \\
\hline N/a & 41 & None & 41 & $\mathrm{~F}$ & 41 & Male & $\mathrm{H}$ & $\mathrm{F}$ & D \\
\hline C5-6 & 42 & Autofusion & 42 & $\mathrm{~F}$ & 42 & Male & $\mathrm{L}$ & $\mathrm{F}$ & D \\
\hline C5-6 & 42 & Autofusion & 42 & $\mathrm{~N}$ & 42 & Male & $\mathrm{L}$ & $\mathrm{N}$ & $\mathrm{C}$ \\
\hline C3-5 & 43 & Stenosis & 43 & $\mathrm{~F}$ & 43 & Male & $\mathrm{H}$ & $\mathrm{F}$ & $\mathrm{D}$ \\
\hline $\mathrm{N} / \mathrm{a}$ & 43 & None & 43 & $\mathrm{~F}$ & 43 & Male & $\mathrm{H}$ & $\mathrm{F}$ & D \\
\hline C3-5 & 43 & Stenosis & 43 & $\mathrm{~N}$ & 43 & Male & $\mathrm{H}$ & $\mathrm{N}$ & A \\
\hline C3-6 & 45 & Stenosis & 45 & $\mathrm{~N}$ & 45 & Male & $\mathrm{H}$ & $\mathrm{N}$ & A \\
\hline C5-6 & 46 & Stenosis & 46 & $\mathrm{~N}$ & 46 & Male & $\mathrm{H}$ & $\mathrm{N}$ & A \\
\hline $\mathrm{N} / \mathrm{a}$ & 47 & None & 47 & $\mathrm{~F}$ & 47 & Female & $\mathrm{H}$ & $\mathrm{F}$ & D \\
\hline $\mathrm{N} / \mathrm{a}$ & 47 & None & 47 & $\mathrm{~N}$ & 47 & Female & $\mathrm{L}$ & $\mathrm{N}$ & $\mathrm{C}$ \\
\hline $\mathrm{N} / \mathrm{a}$ & 48 & None & 48 & $\mathrm{~F}$ & 48 & Male & $\mathrm{H}$ & $\mathrm{F}$ & D \\
\hline$C 2-4 \& 5-7$ & 52 & Autofusion & 52 & $\mathrm{~F}$ & 52 & Male & $\mathrm{L}$ & F & D \\
\hline C6-7 & 53 & Stenosis & 53 & $\mathrm{~N}$ & 53 & Male & $\mathrm{H}$ & $\mathrm{N}$ & $\mathrm{C}$ \\
\hline $\mathrm{C} 2-7$ & 53 & OPLL & 53 & $\mathrm{~N}$ & 53 & Male & $\mathrm{L}$ & $\mathrm{N}$ & B \\
\hline $\mathrm{C} 2-7$ & 54 & Stenosis & 54 & $\mathrm{~F}$ & 54 & Male & $\mathrm{L}$ & F & D \\
\hline C3-4 & 54 & Stenosis & 54 & $\mathrm{~N}$ & 54 & Male & $\mathrm{H}$ & $\mathrm{N}$ & A \\
\hline C3-6 & 55 & Stenosis & 55 & $\mathrm{~F}$ & 55 & Female & $\mathrm{L}$ & $\mathrm{F}$ & $\mathrm{D}$ \\
\hline C3-6 & 58 & Autofusion & 58 & $\mathrm{~F}$ & 58 & Male & $\mathrm{L}$ & F & D \\
\hline
\end{tabular}




\begin{tabular}{|c|c|c|c|c|c|c|c|c|c|c|}
\hline $\mathrm{C} 0-1$ & & 58 & Autofusion & 58 & $\mathrm{~F}$ & 58 & Male & $\mathrm{H}$ & $\mathrm{F}$ & $\mathrm{D}$ \\
\hline C3-7 & & 59 & Stenosis & 59 & $\mathrm{~F}$ & 59 & Female & $\mathrm{L}$ & $\mathrm{F}$ & $\mathrm{D}$ \\
\hline C2-7 & & 59 & Stenosis & 59 & $\mathrm{~F}$ & 59 & Female & $\mathrm{L}$ & $\mathrm{F}$ & D \\
\hline C3-6 & & 59 & Stenosis & 59 & $\mathrm{~N}$ & 59 & Male & $\mathrm{L}$ & $\mathrm{N}$ & $\mathrm{C}$ \\
\hline C2-6 & & 60 & Stenosis & 60 & $\mathrm{~F}$ & 60 & Male & $\mathrm{L}$ & $\mathrm{F}$ & D \\
\hline C4-6 & & 60 & Autofusion & 60 & $\mathrm{~N}$ & 60 & Female & $\mathrm{H}$ & $\mathrm{N}$ & $\mathrm{C}$ \\
\hline $\mathrm{C} 4 / 5$ & & 61 & Stenosis & 61 & $\mathrm{~N}$ & 61 & Male & $\mathrm{L}$ & $\mathrm{N}$ & $\mathrm{C}$ \\
\hline C3-6 & & 61 & Stenosis & 61 & $\mathrm{~N}$ & 61 & Male & $\mathrm{H}$ & $\mathrm{N}$ & B \\
\hline $\mathrm{N} / \mathrm{a}$ & & 69 & None & 69 & $\mathrm{~N}$ & 69 & Male & $\mathrm{H}$ & $\mathrm{N}$ & A \\
\hline C3-6 & & 72 & Stenosis & 72 & $\mathrm{~F}$ & 72 & Male & $\mathrm{H}$ & $\mathrm{F}$ & $\mathrm{D}$ \\
\hline & 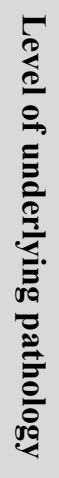 & 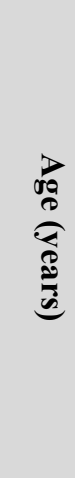 & 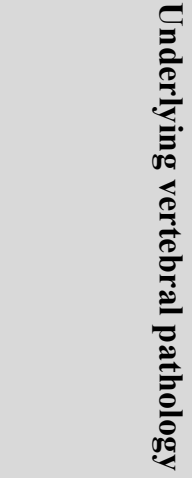 & 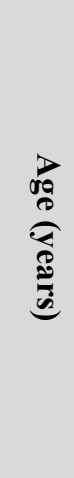 & 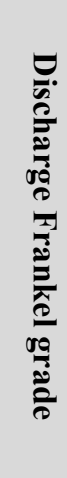 & 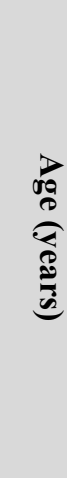 & 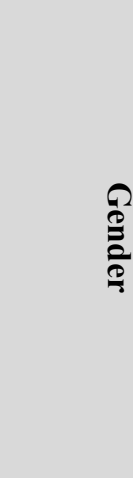 & 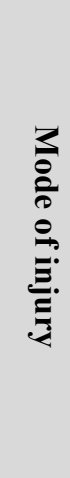 & 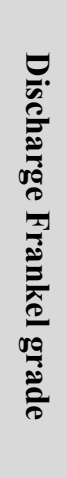 & 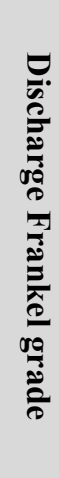 \\
\hline
\end{tabular}

\begin{tabular}{|llll|lll|lllll|}
\hline & & & & & & & & & & & \\
& & & & & & & & & & & \\
& & & & & & & & & & \\
\hline
\end{tabular}




\begin{tabular}{|c|c|c|c|}
\hline \multicolumn{4}{|c|}{ Canal Diameter versus Surgery } \\
\hline \multicolumn{4}{|l|}{ Observed } \\
\hline & No & Yes & Total \\
\hline$<8 \mathrm{~mm}$ & 2 & 25 & 27 \\
\hline$\geq 8 \mathrm{~mm}$ & 18 & 6 & 24 \\
\hline Total & 20 & 31 & 51 \\
\hline \multicolumn{4}{|l|}{ Expected } \\
\hline & No & Yes & Total \\
\hline$<8 \mathrm{~mm}$ & 11 & 16 & 27 \\
\hline$\geq 8 \mathrm{~mm}$ & 9 & 15 & 24 \\
\hline Total & 20 & 31 & 51 \\
\hline \multicolumn{4}{|l|}{ Difference } \\
\hline & No & Yes & Total \\
\hline$<8 \mathrm{~mm}$ & 7.4 & 5 & 12.4 \\
\hline$\geq 8 \mathrm{~mm}$ & 9 & 5.4 & 14.4 \\
\hline Total & 16.4 & 10.4 & 26.8 \\
\hline $\begin{array}{l}\text { Chi Squared } \\
\text { df }\end{array}$ & & & \\
\hline
\end{tabular}

\begin{tabular}{|c|c|c|c|}
\hline \multicolumn{4}{|c|}{ Canal Diameter versus Clinical Improvement } \\
\hline \multicolumn{4}{|l|}{ Observed } \\
\hline & No & Yes & Total \\
\hline$<8 \mathrm{~mm}$ & 17 & 10 & 27 \\
\hline$\geq 8 \mathrm{~mm}$ & 12 & 12 & 24 \\
\hline Total & 29 & 22 & 51 \\
\hline \multicolumn{4}{|l|}{ Expected } \\
\hline & No & Yes & Total \\
\hline$<8 \mathrm{~mm}$ & 15 & 12 & 27 \\
\hline$\geq 8 \mathrm{~mm}$ & 14 & 10 & 24 \\
\hline Total & 29 & 22 & 51 \\
\hline \multicolumn{4}{|l|}{ Difference } \\
\hline & No & Yes & Total \\
\hline$<8 \mathrm{~mm}$ & 0.3 & 0.3 & 0.6 \\
\hline$\geq 8 \mathrm{~mm}$ & 0.3 & 0.4 & 0.7 \\
\hline Total & 0.6 & 0.7 & 1.3 \\
\hline $\begin{array}{l}\text { Chi Squared } \\
\text { df }\end{array}$ & & & \\
\hline
\end{tabular}




\begin{tabular}{|llll|}
\hline Canal Diameter versus Functional Outcome & \\
Observed & & & \\
& No & Yes & Total \\
$<8 \mathrm{~mm}$ & 14 & 13 & 27 \\
$\geq 8 \mathrm{~mm}$ & 5 & 19 & 24 \\
Total & 19 & 32 & 51 \\
& & & \\
Expected & & & \\
& No & Yes & Total \\
$<8 \mathrm{~mm}$ & 10 & 17 & 27 \\
$\geq 8 \mathrm{~mm}$ & 9 & 15 & 24 \\
Total & 19 & 32 & 51 \\
& & & \\
Difference & & & \\
& No & Yes & Total \\
$<8 \mathrm{~mm}$ & 1.6 & 0.9 & 2.5 \\
$\geq 8 \mathrm{~mm}$ & 1.6 & 1.1 & 2.7 \\
Total & 3.2 & 2 & 5.2 \\
& & & \\
Chi Squared & & 0,02030 & \\
df & & 1 & \\
\hline
\end{tabular}

\begin{tabular}{|llll|}
\hline Age versus Surgery & & \\
Observed & & & \\
& No & Yes & Total \\
$\leq 40$ years & 16 & 6 & 22 \\
$>40$ years & 4 & 25 & 29 \\
Total & 20 & 31 & 51 \\
& & & \\
Expected & & & \\
& No & Yes & Total \\
$\leq 40$ years & 9 & 13 & 22 \\
$>40$ years & 11 & 18 & 29 \\
Total & 20 & 31 & 51 \\
& & & \\
Difference & & & \\
& No & Yes & Total \\
$\leq 40$ years & 5.4 & 3.8 & 9.2 \\
$>40$ years & 4.5 & 2.7 & 7.2 \\
Total & 9.9 & 6.5 & 16.4 \\
Chi Squared & & & \\
df & 0,00005 & & \\
\hline
\end{tabular}




\title{
Human Research Ethics Committee Approval Letter
}

\author{
UNTVEASITY OF CAPE TOWN
}

Health Sciences Faculty

Human Research Ethics Committee

Roorn E52-24 Groote 5chuur Hospital Old Main Building

Observatory 7925

Telephone [021] 4066338 • Facsimile [021] 4066411

e-mail: shuretta.thomaselectacia

24 May 2011

HREC REF : 236/2011

Dr C Thompson

Neurosurgery

H53, OMB

Dear Dr Thompson

PROIECT IIILE: HYPEREXTENSION INUURY OF THE CERVICAL SPINE WITH CENTRAL CORD SYNDROME.

Thank you for submitting your study to the Faculty of Health Sciences Human Research Ethics Committee.

It is a pleasure to inform you that the HAFC has formally approved the above-mentioned study.

Approval is granted for one year till the 30 May 2012.

Please submit a progress form, using the standardised Annual Report Form (FHSO16), if the study continues beyond the approval period. Please submit a Standard Closure form (FHSO10) if the study is completed within the approval period.

Please note that the ongoing ethical conduct of the study remains the responsibility of the principal investigator.

Please quote the HREC. AEF in all vour correspondence.

Yours sincerely

signature removed

PROFESSOR M BLOCKMAN

CHAIRPERSON, HSF HUMAN ETHICS

Federal Wide Assurance Number: FWA00001637.

sAmatien 
Dissertations Committee Approval Letter

Dear Crispin Thompson

Candidature Approval (THMCRI001)

\begin{tabular}{|l|l|}
\hline Degree & MMed (Neurosurgery) \\
\hline Title & $\begin{array}{l}\text { Hyperextension Injury of the Cervical Spine } \\
\text { with Central Cord Syndrome }\end{array}$ \\
\hline Department & Surgery \\
\hline Supervisor & Welsh, D \\
\hline Ethics Approval & HREC REF: 236/2011 \\
\hline
\end{tabular}

I am pleased to advise that the Chair of the Dissertations Committee has approved your candidature for the above degree on behalf of the Committee. Formal approval was obtained by publication in the Dean's Circular, Med 07/2011.

Yours sincerely,

Jackie Cogill

Jackie Cogill

Postgraduate Senior Secretary

Room N2.19

Wernher \& Beit Building North

Health Sciences Faculty

Anzio Road

Observatory

7925

Tel: +27 214066750

Email: jackie.cogill@uct.ac.za 


\begin{tabular}{|l|l|l|}
\hline UNIVERSITY OF CAPE TOWN & \\
\hline MMed/MPhil Part III (minor dissertation) & FACULTY OF HEALTH SCIENCES \\
Guidelines for candidates, supervisors and examiners
\end{tabular}

The MMed minor dissertation (or the MPhil dissertation in the case of subspecialities) is one of three examination components of the MMed/MPhil degree. This minor dissertation carries one third of the weight of a full master's dissertation in terms of its credit weighting.

The dissertation must be a study containing the results of an analytical, quantitative, or epidemiological study carried out by the candidate (for certain disciplines, the candidate may chose instead to do a qualitative study, an audit cycle or a formal systemic review). A case report is not acceptable for the dissertation.

The dissertation must be the result of independent work of the candidate conducted under the guidance and direction of a supervisor(s) and should demonstrate evidence of an ability to undertake research, to adequately interpret results and to comprehensively and critically review the relevant literature. Although the findings of the research need not necessarily be original, they must be seen to advance scientific understanding. The topic and scope of research will depend on the particular disciplines and must be agreed upon in consultation with the supervisor(s).

\section{Research protocol}

Candidates intending to register for the MMed/MPhil Part III are required to submit a full research protocol for approval to their respective Departmental Research Committee (DRC). The candidate must also obtain FHS UCT Ethics approval prior to conducting their research. This full research protocol (together 
with a copy of the ethics approval letter) must be submitted to the postgraduate administration for approval by the Board of the Faculty of Health Sciences, prior to commencement of the research. For most disciplines, submission of the research protocol should be made no later than the end of year 2 .

The research protocol should outline the scope and content of the dissertation and must include the title of the proposed dissertation, name of the supervisor(s) and their brief curriculum vitae.

\section{Submission of dissertations}

On completion, the dissertation should be submitted to the Faculty Postgraduate Officer. The candidate should inform the Faculty Officer one month in advance of the intention to submit.

Submission deadlines:

1. March $15^{\text {th }}$ for June graduation

2. August $15^{\text {th }}$ for December graduation

Supervisors will be requested by the Faculty Postgraduate Officer to submit a letter supporting submission. This letter should be supplied by the primary supervisor. If this supervisor is external, the internal supervisor must be kept informed at every stage of the process. Specific submission requirements may be set by individual disciplines. $^{2}$

Note on fees: To avoid attracting fees, dissertations need to be submitted before the beginning of the first quarter (first day of academic year), and before the start of the second semester (mid July) to qualify for a $50 \%$ fee rebate.

\section{Supervisors}

One cannot overemphasize the importance of identifying a dissertation supervisor as early as possible. The supervisor should be an individual who can relate to the candidate's research project, be available for frequent and regular discussion and advice, and someone with whom the candidate can develop a good working relationship. Where specialised equipment and/or laboratory work is required for the study, the supervisor should assist in facilitating such access to such facilities. 
Supervisors may assist candidates in developing scientific communication skills but they are not required to do detailed editing or correction of spelling, grammar, or style. They may refer candidates to the UCT Writing Centre for this purpose.

The primary supervisor may be based outside the candidate's home department, faculty or university. In such a case, an internal (or secondary) supervisor will be required in addition to the primary supervisor, to serve as a guide and link to discipline-specific procedures. Primary supervisors retain responsibilities to the candidate and the university until the dissertation process is complete.

Please note: in order to assist a candidate with a master's research topic the supervisor needs to hold a master's degree or higher, or have relevant research experience. If the primary supervisor does not hold a higher degree or equivalent (such as a Fellowship of The College of Medicine of South Africa), then a secondary supervisor who has a higher degree will need to be appointed in addition to the primary supervisor.

Candidates are strongly encouraged to publish the study with the supervisor(s) as coauthor(s). This may require work beyond the graduation date. Such arrangements should be discussed and documented in advance.

2 For Public Health Medicine and Occupational Medicine the dissertation must be submitted for examination at least 4 months prior to the deadline for registration for the examinations of the relevant College. This is in order to ensure that a final examination mark for the dissertation can be submitted by the candidate to the College of Medicine of South Africa (CMSA) at the time of registration as required by CMSA examination regulations.

\section{The dissertation}

Submission of the dissertation should satisfy the following criteria:

1. The title page should contain the candidate's name, dissertation title and the name of the university. It must also state the degree, e.g. Master of Medicine (MMed) in Public Health Medicine, Occupational Medicine, Family Medicine, Surgery, etc. The title page should also include a statement to the effect that the research report is based on independent work performed by the candidate and that neither the 
whole work nor any part of it has been, is being, or is to be submitted for another degree to any other university. It must also state that this work has not been published prior to registration for the abovementioned degree.

2. The body of the dissertation, which must be structured in 4 parts, should include the following:

Part A: The protocol (as approved by the Departmental Research Committee and Faculty Research Ethics Committee). The protocol should not exceed 4000 words.

Part B: A structured literature review appropriate to the subject matter and methods of the dissertation. The literature review must, amongst other things, show that the student is sufficiently acquainted with the relevant literature and is able to perform a critical appraisal and, if appropriate for the topic, show a good understanding of evidence-based medicine.

The review should be between 3000 and 4000 words.

A suggested structure for the literature review is as follows:

a) Objectives of literature review

b) Literature search strategy, including inclusion and exclusion criteria

c) Quality criteria - some leeway will be allowed here, as candidates will vary in their ability to appraise studies. This will also vary with the nature of the dissertation.

d) Summary or interpretation of literature

e) Identification of gaps or needs for further research

f) References (which will overlap with but will not be the same lists as in the journal article and protocol)

Part C: The results of the study must be presented in the form of a manuscript of an article for a named peer reviewed journal, meeting all the requirements set out in the "Instructions for Authors" of that journal, including the word count and referencing style. (Unless specially motivated, the journal chosen will need to allow for at least 3000 words excluding abstract, tables, figures and references). The "Instructions to Authors" of the journal must be appended. The journal 
chosen for publication must be appropriate to the subject matter of the dissertation and accredited by the Department of Education or listed in the citation index of the Institute for Scientific Information (ISI).

Important note: the candidate need not have submitted the article, not is the acceptance of the article and requirement for passing the degree. The norm of practise is to publish the study with the supervisor(s) as co-author(s) and candidates are strongly encouraged to submit their manuscript either before or after examination of the mini-dissertation.

Part D: All supporting documents including:

- Questionnaire/data capture instrument

- Consent forms and any related participant information sheets

- Technical appendices, including, if considered necessary, any additional tables not included in the main manuscript for the examiner to have available. These should be accompanied by a brief narrative.

- Official Ethics approval letter from the Faculty Research Ethics Committee

3. The article does not have to be submitted to the journal in order to meet academic requirements.

4. A candidate must submit 2 copies of the dissertation in temporary binding, and an electronic copy on compact disc in a universally readable format (e.g. pdf).

\section{Examiners}

The full dissertation will be submitted for examination through the Postgraduate office of our Faculty to two external examiners (nominated by the supervisors and HOD).Three examiners will be nominated, two of which are invited to examine, and one held as an alternate. All examiners must be external to UCT. These nominations are circulated to the Faculty Dissertation Committee. It is the supervisor's (or cosupervisor's) responsibility to submit names of potential examiners to the Faculty Officer when the candidate is ready to submit. 
The examiners will be well briefed regarding the specific requirements and criteria for submission and examination of the mini-dissertation. Such criteria will clearly explain the difference between the mini-dissertation and a Master's degree by dissertation alone.

Details required for each examiner are: academic qualifications, postal and/or physical address, telephone and fax numbers and e-mail address, and one paragraph description of their standing in the relevant field (drawn from their $\mathrm{CV}$ if need be.)

The candidate may not be informed of the identity of the examiners. After the outcome of the mini-dissertation has been finalised, the examiners' identities are made known if the examiners have indicated that they do not object to this. 


\section{GUIDELINES ON THE LAYOUT AND STYLE OF THE DISSERTATION OR}

\section{THESIS}

To assist you in organising the presentation of your dissertation, the guidelines below may be useful.

\section{DISCUSSION WITH SUPERVISOR REGARDING DISSERTATION/THESIS}

Discuss the layout of your dissertation/thesis with your supervisor. During this discussion you will decide what sections to include in the dissertation/thesis, such as:

- The abstract which forms the preface of the dissertation/thesis

- Introduction

- Section on the study design and research methods used

- How many chapters there will be and what each chapter should encapsulate

- The conclusion or summary section

Please note: Supervisors, although they may assist with this, are not required to do detailed editing nor correction of spelling and grammar, or style. Students who need assistance in academic writing are encouraged to make use of support services available, e.g. The UCT Writing Centre.

\section{PAGE SET-UP:}

- Left margin at least $4 \mathrm{~cm}$; right margin about $2.5 \mathrm{~cm}$. This will allow for the binding of the dissertation/thesis

- Use A4page set-up

- Page numbers in the same font as the font you are using for the text. Use fonts such as Arial, Times New Roman, Book Antiqua, or Bookman Old Style. Avoid the "comic" fonts.

- Font size 11 or 12

- Set language to English [South Africa] - avoid the American spellings e.g. behavior 
- Line spacing of 1.5 is recommended. We also suggest that you set your spacing to allow 6pts after each paragraph - this improves the look of the document and you don't have to put in an extra paragraph break.

\section{GENERAL SUGGESTIONS}

- Make sure that your tables, graphs, and other graphics are properly numbered and that you refer to them correctly

- Make sure that your write in an easily understood manner. Don't make paragraphs consisting of one sentence. Use shorter rather than long, complicated sentences. Academic writing is meant to be clear, not jargon! The ideal is one idea/thought/result per sentence.

- Mind your grammar

- When you use a term in full (for which there is an acknowledged abbreviation) the first time then put the abbreviation in brackets. After that you can use the abbreviation, but ensure that you write it down correctly. It is always a good idea to include a list of abbreviations used in your text. This will be included in the text just after the Table of Contents

- When you use lots of technical terms it may be a good idea to include a glossary of terms used. You will insert this after the list of abbreviations

- Always do a spell-check once you have completed a paragraph or a section. This will be easier and faster than running a spell-check right at the end. Be very particular with the spelling because there is nothing that irks an examiner as much as spelling error after spelling error.

- Print on only one side of the page

- Decide on which referencing method you will be using and ensure that you do not deviate from that. It is a good idea to stipulate somewhere which referencing method you are using

\section{PRINTING OF THE DISSERTATION/THESIS}

- Master's candidates must submit two copies of the dissertation in temporary binding (e.g. ring binding) for examination, and a CD containing the dissertation in one continuous file in a universally readable format. Master's candidates must submit their dissertations to the Manager: Postgraduate Administration on the specified dates (see Dates to Remember below)

- Doctoral candidates (MD) must submit three copies of the thesis. Three (3) copies must be temporary binding, and a CD containing the dissertation in one continuous file in a universally readable format.

- Doctoral candidates (MD) must submit their theses to the DDB Officer on the specified dates (see Dates to Remember below)

- Doctoral candidates must submit 3 copies of the thesis in temporary binding, and a $\mathrm{CD}$ containing the thesis in one continuous file in a universally readable format. Doctoral candidates must submit their theses to the DDB Officer on the specified dates (see Dates to Remember below) 


\section{Title PAGE}

Title of dissertation
by
STUDENT: FULL NAMES
STUDENT NUMBER
SUBMITTED TO THE UNIVERSITY OF CAPE TOWN
In (partial if the degree was by coursework AND dissertation) fulfilment of the requirements
for the degree
M Sc.... (name of degree)
Faculty of Health Sciences
UNIVERSITY OF CAPE TOWN
Date
Supervisor [s]:
Name and Department and University
of




\section{DECLARATION PAGE}

You must include a signed and dated declaration in the front of your dissertation/thesis. Please use the standard format shown below:

\section{DECLARATION}

I, $\ldots \ldots \ldots \ldots \ldots \ldots \ldots \ldots \ldots$, hereby declare that the work on which this dissertation/thesis is based is my original work (except where acknowledgements indicate otherwise) and that neither the whole work nor any part of it has been, is being, or is to be submitted for another degree in this or any other university.

I empower the university to reproduce for the purpose of research either the whole or any portion of the contents in any manner whatsoever.

Signature:

Date: 


\section{DATES TO REMEMBER FOR 2011}

\section{Master's candidates}

\section{JUNE GRADUATION}

If you wish to graduate in June 2011 then you have to:

- Give a letter of Intention to submit to the Manager of the Postgraduate Unit not later than 15 January 2011

- Submit your dissertation by not later than 05 March 2011

[Note 1: If you submit your dissertation before the start of the new academic year (05 February 2011) then you do not have to reregister or pay fees again.

Note 2: If, however, you receive a grade of "Revise and Resubmit" then you must reregister and pay fees again w.e.f. the date on which you received the notification of the result]

\section{DECEMBER GRADUATION}

If you wish to graduate in December of any particular year then you have to:

- Give a letter of Intention to submit to the Manager of the Postgraduate Unit not later than 20 July of that year

- Submit your dissertation by not later than 15 August of that year 


\title{
Doctoral Candidates
}

\author{
JUNE GRADUATION
}

If you wish to graduate in June 2011 then you have to:

- Give a letter of Intention to submit to the Administrator of the Doctoral Degrees Board not later than 10 January 2011

- Submit your thesis by not later than 05 February 2011

[Note 1: If you submit your thesis before the start of the new academic year (05 February 2011) then you do not have to reregister or pay fees again.

Note 2: If, however, you receive a grade of "Revise and Resubmit" then you must reregister and pay fees again w.e.f. the date on which you received the notification of the result]

\section{DECEMBER GRADUATION}

If you wish to graduate in December of any particular year then you have to:

- Give a letter of Intention to submit to the Administrator of the Doctoral Degrees Board not later than 20 June of that year

- Submit your thesis by not later than 15 August of that year 


\title{
European Spine Journal
}

\author{
Info for articles
}

\section{Types of papers}

Original Articles should have no more than 2,500 words with an abstract of 150 words and 25 references

Review Articles should have no more than 3,500 words and 50-70 references

Letters to the Editor are limited to 500 words and 5 references

\section{Manuscript Submission}

Submission of a manuscript implies: that the work described has not been published before; that it is not under consideration for publication anywhere else; that its publication has been approved by all co-authors, if any, as well as by the responsible authorities - tacitly or explicitly - at the institute where the work has been carried out. The publisher will not be held legally responsible should there be any claims for compensation.

\section{Permissions}

Authors wishing to include figures, tables, or text passages that have already been published elsewhere are required to obtain permission from the copyright owner(s) for both the print and online format and to include evidence that such permission has been granted when submitting their papers. Any material received without such evidence will be assumed to originate from the authors.

\section{Online Submission}

Authors should submit their manuscripts online. Electronic submission substantially reduces the editorial processing and reviewing times and shortens overall publication times. Please follow the hyperlink "Submit online" on the right and upload all of your manuscript files following the instructions given on the screen. 


\title{
Title Page
}

The title page should include:

The name(s) of the author(s)

A concise and informative title

The affiliation(s) and address(es) of the author(s)

The e-mail address, telephone and fax numbers of the corresponding author

\begin{abstract}
Please provide an abstract of 150 to 250 words. The abstract should not contain any undefined abbreviations or unspecified references.
\end{abstract}

\section{Keywords}

Please provide 4 to 6 keywords that can be used for indexing purposes.

\section{Text Formatting}

Manuscripts should be submitted in Word.

Use a normal, plain font (e.g., 10-point Times Roman) for text.

Use italics for emphasis.

Use the automatic page numbering function to number the pages.

Do not use field functions.

Use tab stops or other commands for indents, not the space bar.

Use the table function, not spreadsheets, to make tables.

Use the equation editor or MathType for equations.

Note: If you use Word 2007, do not create the equations with the default equation editor but use the Microsoft equation editor or MathType instead.

Save your file in doc format. Do not submit docx files.

Manuscripts with mathematical content can also be submitted in LaTeX.

\section{Headings}

Please use no more than three levels of displayed headings.

\section{Abbreviations}

Abbreviations should be defined at first mention and used consistently thereafter. 


\section{Footnotes}

Footnotes can be used to give additional information, which may include the citation of a reference included in the reference list. They should not consist solely of a reference citation, and they should never include the bibliographic details of a reference. They should also not contain any figures or tables.

Footnotes to the text are numbered consecutively; those to tables should be indicated by superscript lower-case letters (or asterisks for significance values and other statistical data). Footnotes to the title or the authors of the article are not given reference symbols.

Always use footnotes instead of endnotes.

\section{Acknowledgments}

Acknowledgments of people, grants, funds, etc. should be placed in a separate section before the reference list. The names of funding organizations should be written in full.

\section{References}

\section{Citation}

Reference citations in the text should be identified by numbers in square brackets. Some examples:

1. Negotiation research spans many disciplines [3].

2. This result was later contradicted by Becker and Seligman [5].

3. This effect has been widely studied $[1-3,7]$.

Reference list

The list of references should only include works that are cited in the text and that have been published or accepted for publication. Personal communications and unpublished works should only be mentioned in the text. Do not use footnotes or endnotes as a substitute for a reference list.

The entries in the list should be numbered consecutively.

Journal article

Gamelin FX, Baquet G, Berthoin S, Thevenet D, Nourry C, Nottin S, Bosquet L (2009) Effect of high intensity intermittent training on heart rate variability 
in prepubescent children. Eur J Appl Physiol 105:731-738. doi: $10.1007 / \mathrm{s} 00421-008-0955-8$

Ideally, the names of all authors should be provided, but the usage of "et al" in long author lists will also be accepted:

Smith J, Jones M Jr, Houghton L et al (1999) Future of health insurance. N Engl J Med 965:325-329

\section{Article by DOI}

Slifka MK, Whitton JL (2000) Clinical implications of dysregulated cytokine production. J Mol Med. Doi:10.1007/s001090000086

Book

South J, Blass B (2001) The future of modern genomics. Blackwell, London

Book chapter

Brown B, Aaron M (2001) The politics of nature. In: Smith J (ed) The rise of modern genomics, 3rd edn. Wiley, New York, pp 230-257

Online document

Doe J (1999) Title of subordinate document. In: The dictionary of substances and their effects. Royal Society of Chemistry. Available via DIALOG. http://www.rsc.org/dose/title of subordinate document. Accessed 15 Jan 1999

\section{Dissertation}

Trent JW (1975) Experimental acute renal failure. Dissertation, University of California

Always use the standard abbreviation of a journal's name according to the ISSN List of Title Word Abbreviations, see www.issn.org/2-22661-LTWA-online.php 